\title{
Design for additive manufacturing of composite materials and potential alloys: a review
}

\author{
Hussien A. Hegab* \\ Department of Mechanical Design and Production Engineering, Cairo University, 12613 Giza, Egypt
}

Received 1 December 2015 / Accepted 23 May 2016

\begin{abstract}
As a first step of applying additive manufacturing (AM) technology, plastic prototypes have been produced using various AM Process such as Fusion Deposition Modeling (FDM), Stereolithography (SLA) and other processes. After more research and development, AM has become capable of producing complex net shaped in materials which can be used in applicable parts. These materials include metals, ceramics, and composites. Polymers and metals are considered as commercially available materials for AM processes; however, ceramics and composites are still considered under research and development. In this study, a literature review on design for AM of composite materials and potential alloys is discussed. It is investigated that polymer matrix, ceramic matrix, metal matrix, and fiber reinforced are most common composites through AM. Furthermore, Functionally Graded Materials (FGM) is considered as an effective application of AM because AM offers the ability to control the composition and optimize the properties of the built part. An example of FGM through using AM technology is the missile nose cone which includes an ultra-high temperature ceramic graded to a refractory metal from outside to inside and it used for sustaining extreme external temperatures. During this work, different applications of AM on different classifications of composite materials are shown through studying of industrial objective, the importance of application, processing, results and future challenges.
\end{abstract}

Key words: Additive manufacturing, Metal matrix composites, Polymer matrix composites, Nano-composite materials, Ceramic matrix composite, Functionally graded material

\section{Introduction}

Additive Manufacturing (AM) is considered as a smartdeveloped manufacturing technique based on adding materials layer by layer for making three-dimensional parts directly through using Computer Aided Design (CAD) models. The most important advantage of AM rather than removing materials or another manufacturing process is dealing with geometric and material complexities which cannot be created using subtractive manufacturing processes.

A lot of research studies are obtained the different working principles of AM process, but the category which based on the state of starting material is considered as the most common used. Table 1 shows the state of starting material working principle for AM processes with respect to other criterions such as; process, layer creation technique and typical materials $[1,2]$. In modern technology applications materials with unusual combinations of properties, which cannot be provided

*Corresponding author: hegab@aucegypt.edu using conventional metal alloys, ceramics or polymers, are needed. Composite materials allow us to combine the preferred properties in one material by synthesizing a new material using two or more materials having the desired properties. The resultant material has a proportion of the desired property of each of the constituent materials [3]. There are a lot of research challenges and opportunities in the area of AM technology. Important requirement to face some of those challenges is developing a national user standards testing facility to test and refine of AM methodologies. Creating Finite Element Analysis (FEA) module for analyzing of main AM processes is considered as a smart developing step to model and simulate of AM technology. Developing a cost modeling software and a set of additive manufacturing design guidelines for each specific field (automotive, biomedical, aerospace...) are one of research opportunities to improve this technology. The investigation, development, and commercialization for the creation of a set of new material with unusual combinations of properties are required, so studying the application of AM technology through composite material and nano-composites became an 
Table 1. Analysis of the state of starting material working principle for AM processes [1].

\begin{tabular}{|c|c|c|c|c|c|}
\hline $\begin{array}{l}\text { State of starting } \\
\text { material }\end{array}$ & Process & Material preparation & Layer creation method & Typical materials & Applications \\
\hline Filament & FDM & Melted in nozzle & $\begin{array}{l}\text { Continuous extrusion \& } \\
\text { deposition }\end{array}$ & Thermoplastics, waxes & Prototypes, casting patterns \\
\hline \multirow[t]{3}{*}{ Liquid } & SLA & Resin in a vat & Laser scanning & $\begin{array}{l}\text { UV curable resin, } \\
\text { ceramic suspension }\end{array}$ & Prototypes, casting patterns \\
\hline & MJM & Polymer in jet & Ink-jet printing & Acrylic plastic, wax & Prototypes, casting patterns \\
\hline & SLM & Powder in bed & Laser scanning & Metal & Tooling, functional parts \\
\hline \multirow[t]{2}{*}{ Powder } & EBM & Powder in bed & Electron beams scanning & Metal & Tooling, functional parts \\
\hline & $3 \mathrm{DP}$ & Powder in bed & $\begin{array}{l}\text { Drop-on-demand binder } \\
\text { printing }\end{array}$ & $\begin{array}{l}\text { Polymer, metal, ceramic, } \\
\text { other powders }\end{array}$ & $\begin{array}{l}\text { Prototypes, casting shells, } \\
\text { tooling }\end{array}$ \\
\hline Solid sheet & LOM & Laser cutting & $\begin{array}{l}\text { Feeding and binding } \\
\text { of sheets with adhesives }\end{array}$ & Paper, plastic, metal & Prototypes, casting models \\
\hline
\end{tabular}

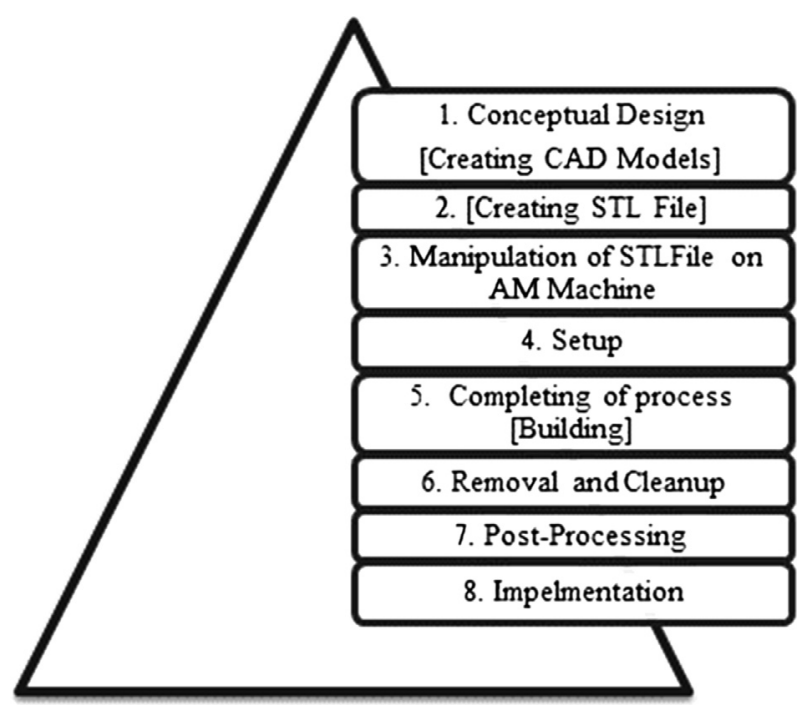

Figure 1. AM technology steps.

important area of research [4]. Conceptual and functional prototypes were fabricated within last 30 years using AM through several proposed systems. AM technology has a lot of systems; all of them have many similarities and some distinctions as well. The first commercialized AM process was Stereolithography (SLA), it depends on solidification of liquid photopolymer by using a concentrated beam of the ultraviolet lamp in order to create a contour of the two-dimensional layer. After completing of the first layer, the build platform will move downwards in the $z$ direction to create a new layer of photopolymer. Examples of other commercialized AM processes are laser sintering, laser melting, fusion deposition modeling, multi-jet modeling, electron beam melting, laminated object manufacturing, plaster-based 3D printing, laser engineered net shaping, shaped metal deposition, and powder bed-inkjet head 3D printing [5]. There are a lot of capabilities for AM implementation and adoption in industry; some of these are [6]:

I. Geometric freedom,

II. Part functionality,

III. Economic low volume production,

IV. Environmental sustainability.

It is obtained that investigation, development and commercialization of AM technology and materials are the main scope of research in this area nowadays. AM has a lot of significant applications such as automotive, aerospace, energy, biomedical, and other fields [7, 8]. Figure 1 shows the sequence of steps of AM technology starting from conceptual design till implementation step [8]. A lot of needs support AM technology implementation in different effective areas, such as [9, 10]:

I. Improve population health and quality of life through customization of healthcare products.

II. Reduce the impact of environment on manufacturing sustainability.

III. Increase the efficiency in demand fulfillment by simplification of the supply chain system.

IV. Applying monitoring techniques such as; sensors for measuring and monitoring AM processes and process.

V. Validation of physics and properties of AM models.

The main objective of this work is studying AM technology through different types of composite materials because of the importance of these materials as mentioned before. 

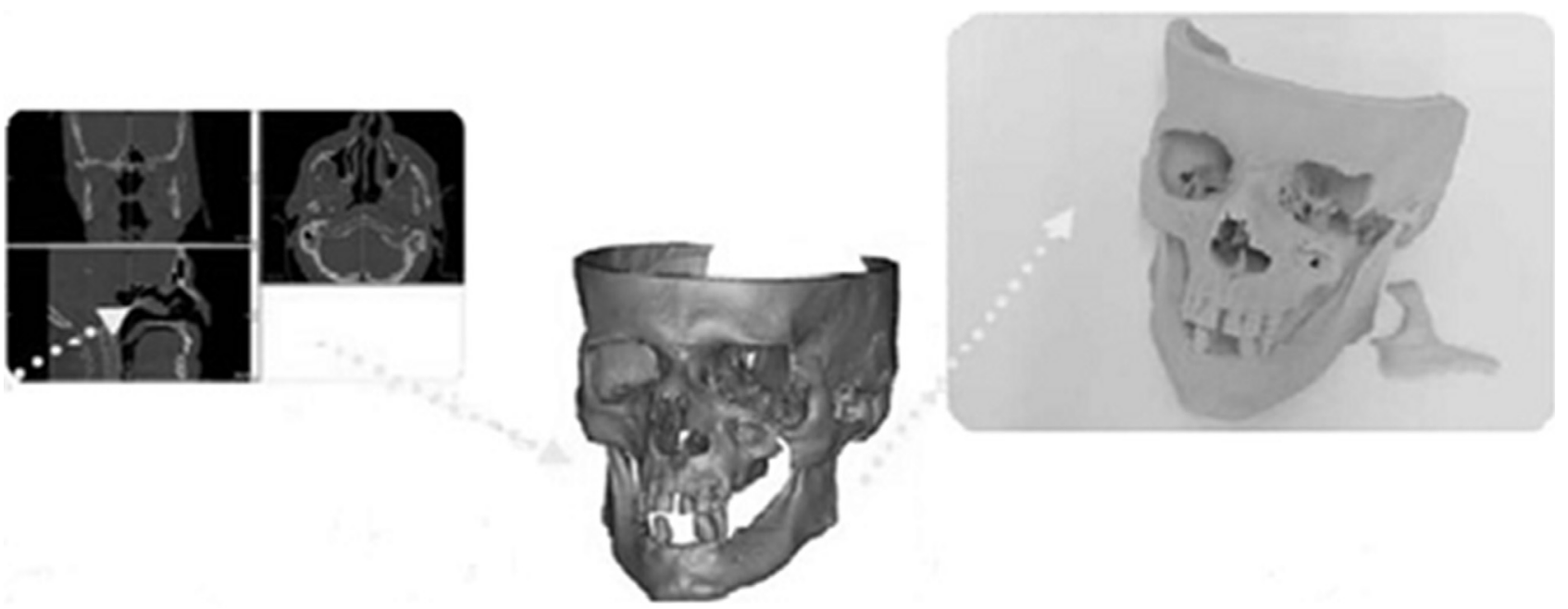

Figure 2. CT-scan examples in biomedical sector.

\section{AM applications and materials}

Adding value to products and increase their quality is considered as an effective advantage of applying AM technology. This section is going to review most common products fabricated using AM technology in different fields $[7,11]$.

\subsection{Polymeric products}

One of the most suitable processes in fabrication polymeric products through AM is called High-Speed Sintering (HSS). The process concept is based on using radiation absorbing material (RAM) to print the desired area and then sintering using infrared (IR) radiation, so it can be a promising competitor with injection moulding processes [12]. The main application of polymers through AM is a fabrication of polymer prototypes which use for visual validation and validation of assemblies. Polymers can be used too in biomedical applications through two main categories which are biocompatible polymers and biodegradable polymers. The biocompatible polymers can be used for external and internal use in the biomedical sector. An example of external used is the hearing aid industries because of the rigidity and durability of polymeric material used (the EnvisionTEC e-Shell 200 series). On the other hand, examples of internal use are coronary bypass implant with very small internal channels and hard tissue lumbar implants. Regarding the biodegradable polymers, it has an effective role in the construction of human organs and real tissue engineering $[7,11]$. Also, polymeric materials have an application in artistic and jewelry designs as it serves for modeling based on vacuum investment casting and jewels themselves [11].

\subsection{Metallic products}

One of most metallic applications using AM technology is tooling design. AM has the ability to manufacture free-form cooling channels with inclined complex shape rather than cooling channels which obtained by drilling in conventional mould fabrication (normally straight). Implementation of AM technology offers a completely homogeneous heat transfer, adaptive cooling [11]. In general, laser or electron beam-based are used in metallic applications, especially in fabricating hybrid moulds as it is easy to create mould inserts over the prefabricated mould and it leads to saving time and costs, furthermore process characteristics are improved [11, 13]. In addition to metallic applications in tooling, it has an important application in the biomedical sector, especially in obtaining complex details in osseous structure. Furthermore, using Computerized Tomography (CT) leads to speed up the overall biomedical product development rather than using conventional processes as it became easy for scanning, converting to a model, exporting to STL file, slicing, and fabrication. One other advantage is reducing of surgical intervention time $[10,11]$. An example of CT-scan in the biomedical sector is shown in Figure 2. Metallic AM has three different categories of material processing depend on AM process used, build volume and energy source used. Those categories are powder bed systems, powder feed systems, and wire feed systems as shown in Figure 3 [7, 10]. Other classifications of AM metallic processes depend on the way of bonding between metal particles; indirect or direct method. The examples of AM processes used in the indirect technique are SLS, 3DP, FDM, SLA, and LOM, while the examples used for the direct techniques are SLM, LMD and EBM [7, 10, 14].

\subsection{Aerospace and automotive applications}

A lot of research has been done to improve fuel efficiency and engine life by using AM technology through achieving unattainable properties. For example, Ti6Al4V was investigated using EBM because of its effective impact in automotive engine components especially, pistons and engine exhaust valves and high potential characteristics of Ti6Al4V as well (low density and high specific strength) [7, 11, 15]. An example of blisk repairing using AM technology is shown in 


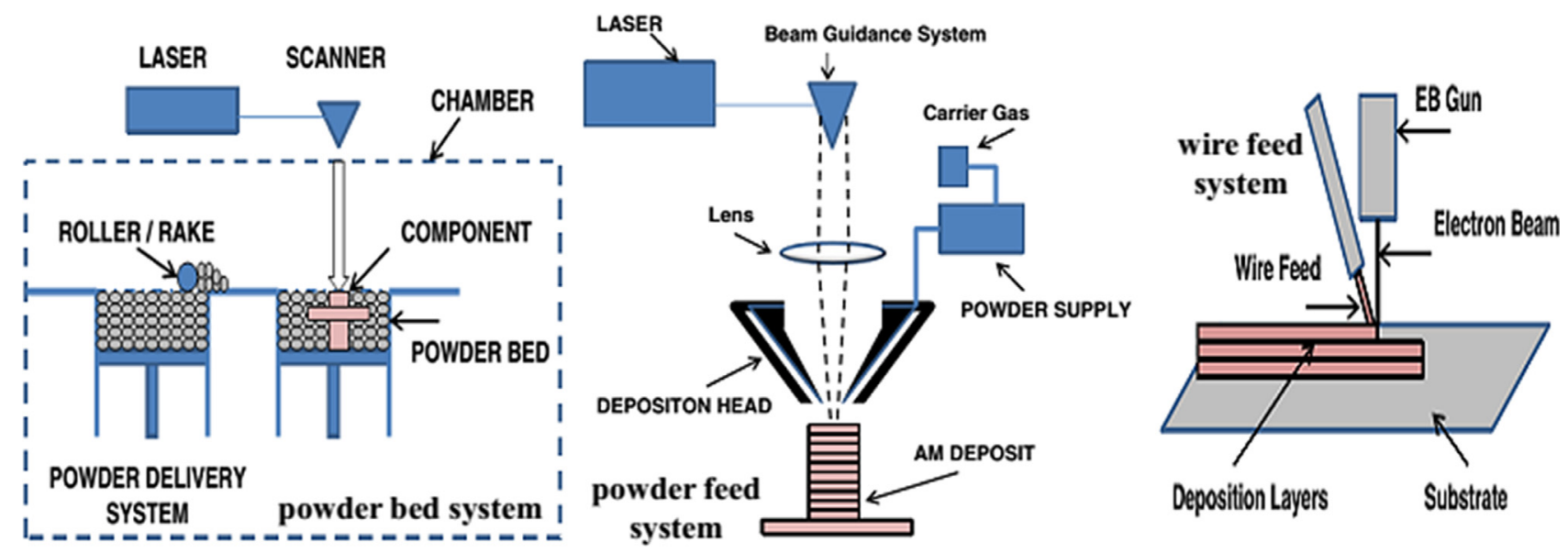

Figure 3. Material processing of metallic AM [7].
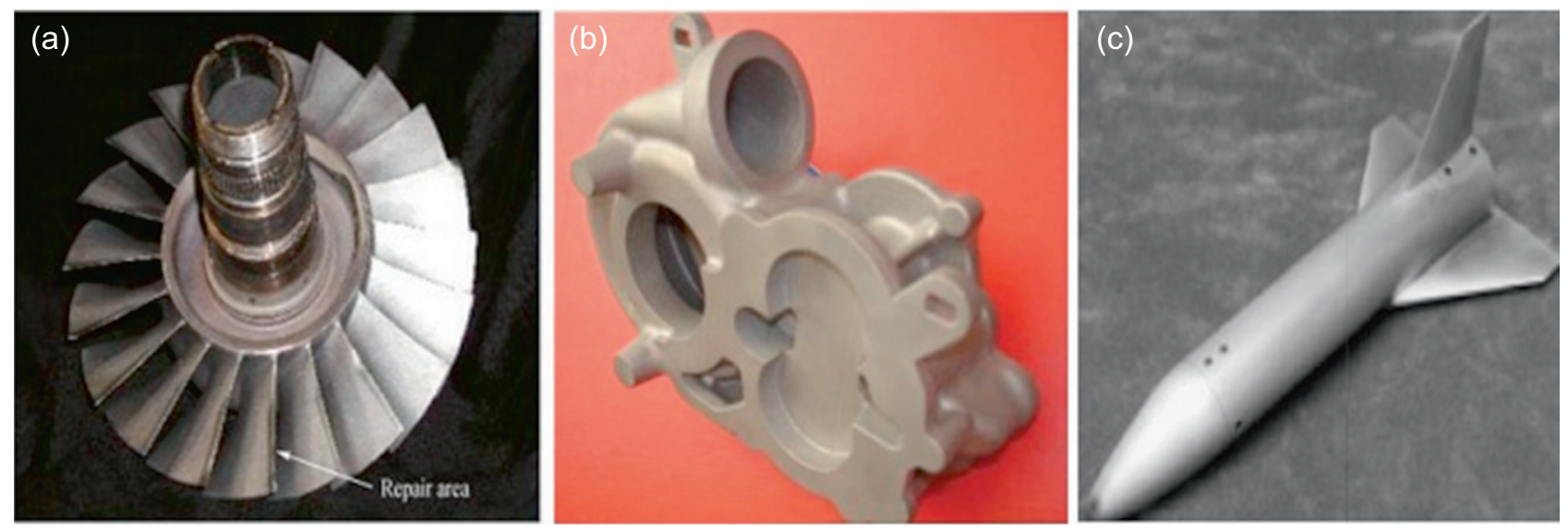

Figure 4. AM applications of aerospace and automotive [7].

Figure 4a. On the other hand, National Research Council Canada (NRCC) has tested the mechanical properties of several materials (Ti6Al4V, Fe-based tool steel...) using LMD process and the results are the same or better than the mechanical properties of conventional materials. Another application is using AM for building wind tunnel test models for aircraft, missiles, etc. [7]. Furthermore, AM is used to repair aerospace components such as; Fraunhofer ILT (Germany) and Rolls-Royce Deutschland has achieved progress using LMD in repairing of 15 applications includes; high-pressure turbine case, compressor front drum, blisk, rotors, airfoils, etc. [16]. An example of wind tunnel testing produced by using SLS of wing-body-tail launch model is provided in Figure 4c. Aerospace applications haven't been limited by using only metals, as ceramic parts are used especially ultra-high temperature ceramics $(\mathrm{ZrB} 2, \mathrm{ZrC})$ which can withstand more $2000{ }^{\circ} \mathrm{C}$. Examples of aerospace ceramic parts are hypersonic flight systems and rocket propulsion systems which have more complex geometries using SLS process [17]. At the end of this section, the mechanical properties of different materials which processed by using some of AM processes are given as shown in Table 2 [7, 18, 19]. In term of automotive application, AM technology has been used in the fabrication of small quantities of structural parts, such as engine exhausts, drive shafts, gearbox components and braking system. Furthermore, it is considered as a successful technology for manufacturing of functional components for racing vehicles. SLS, SLM, and EBM are used in the fabrication of titanium gearbox, motorbike dashboards, camshaft covers, and suspension systems. An example of using SLM to produce water pump for a motorsports car is obtained in Figure $4 \mathrm{~b}$. As results of using this design and fabrication techniques, around $25 \%$ weight savings has been achieved and other performance characteristics have been improved such as torsion stiffness, wear, and power absorption. A 3DP rapid casting technique is used for engine components fabrication. This technique has an effective impact in the reduction of the development time. For example, shape engine block can be manufactured during 1 week, although it includes cooling passages and oil recirculation lines which are very complex in design [7, 11]. In order to develop AM technology and achieving an interactive effect in different industry applications, more research, investigation, and studying of AM effects on composites are required. In the next section, different categories of composite materials and their impact on AM technology are discussed. It is investigated that fabrication of lattice structures is an 
Table 2. Mechanical properties of some metallic AM proposed materials.

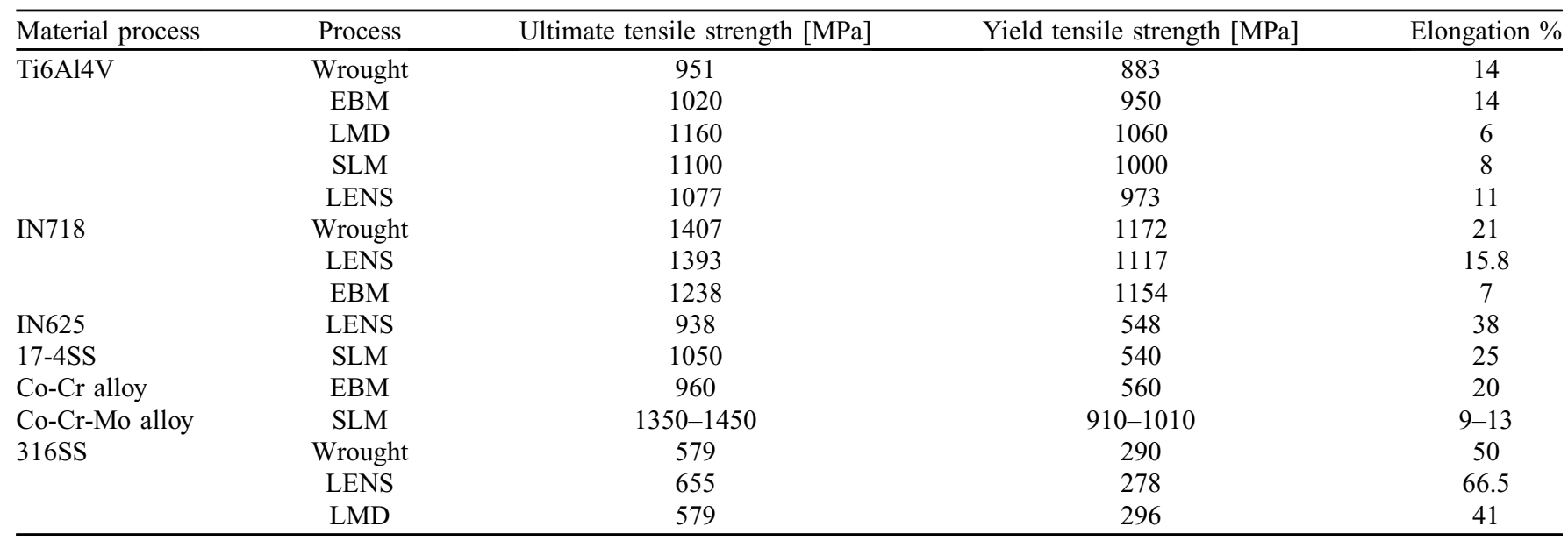

important criterion in aerospace and automotive applications as it provides the structure with the high strength-to-weight ratio. Furthermore, AM technology supports these types of structures with a gradual and controlled porosity which cannot be achieved using fabrication conventional processes. The advantages of using AM in fabrication of aerospace and automotive applications are concluded; weight reduction (raw materials), decreasing use of the energy (fuel consumption), decreasing in the weight ratio between the raw material used for a component and the weight of the component itself (buy-to-fly ratios) and providing geometric freedom $[7,10]$.

\section{Additive manufacturing technology of composite materials and potential alloys}

Composite materials offer unusual combinations of properties and AM processes have a lot of advantages for fabrication complex shapes and sustaining or improving product characteristics as well. Investigation of AM technology effects on composite materials is still in the area of research, but numbers of researchers have tried to study those effects through different categories of composite materials. Furthermore, potential alloys which have an impact in industry applications and provides effective properties are discussed. In this review, metal matrix, metallic alloys, ceramic matrix, polymer matrix, structural composites and nano-composite are discussed through analyzing of different case studies.

\subsection{Metal matrix composites and metallic alloys}

Metal matrix composites (MMC) are composites in which the matrix phase is a ductile metal. The metal matrix provides ductility and thermal stability for the composite at elevated temperatures, while the fiber may increase the strength, the stiffness, enhance the resistance to creep or abrasion, and improve the thermal conductivity. Aluminum and its alloys, copper, titanium, and magnesium are most common metals used in MMCs. Metal matrix composites can be divided into three different categories: related to the type of reinforcement, fiber, or particulate. The most common fabrication processes for MMC are powder metallurgy, spray deposition and squeeze casting $[3,20]$. As an extension of studying ultrasonic additive manufacturing on $\mathrm{NiTi}-\mathrm{Al}$, another work has been done to investigate the bonding between the fiber and matrix in composites fabricated and the shear strength of the fiber-matrix interface. Al 3003-H18 is used as matrix phase and with prestrained $\mathrm{NiTi}$ embedded inside. Composite failure temperatures have been observed by using differential scanning calorimetry. The constitutive models of the NiTi element and Al matrix have investigated average interface shear strength of 7.28 $\mathrm{MPa}$ and an effective coefficient of thermal expansion of zero at $135{ }^{\circ} \mathrm{C}$. Furthermore, interface failure temperatures can be increased as the embedded fiber length is increased. Mechanical nature is observed after studying of the bonding between the fiber and interface using energy dispersive X-ray spectroscopy, but no evidence to support chemical or metallurgical bonding. De-bonding evidence and ribbon contraction SEM images (interior surface of the $\mathrm{Al}$ matrix) is found [21]. Ultrasonic additive manufacturing (rapid prototyping process) based on ultrasonic metal welding has been used to develop active aluminum matrix composites. This composites material is consists of aluminum matrices and embedded shape memory NiTi, magnetostrictive Galfenol, and electro-active PVDF phases. One of the most important advantages of this process is working at temperatures as low as $25^{\circ} \mathrm{C}$ during fabrication rather than other metal-matrix fabrication processes which require temperatures of $500{ }^{\circ} \mathrm{C}$. The results of this research have been obtained as; the electrical insulation of embedded materials from the ultrasonic additive manufacturing matrix can be achieved (between NiTi and $\mathrm{Al}$ phases), up to $22.3 \%$ NiTi volume fraction can be created without any effect of their resulting dimensional stability and thermal actuation characteristics, Galfenol-Al composite has the ability to provide magnetic actuation (medium permittivity) of up to $54 \mu \epsilon$, and PVDF-Al composite sensor has been created and tested successfully [22]. Ti, Ni, and Fe-based alloys powder are considered as the most common mature phase of additive manufacturing practical applications. A complete melting mechanism using LM or LMD is the most basic processing 
technique for those types of alloys because of easy process controllability. The main effective type of Ti-based alloys is Ti-6Al-4V because it has a lot of applications in aerospace and medical fields. Regarding Ni-based alloys; Inconel 625 and 718 are the most common used because they have an improved tensile properties, corrosion, creep balance, oxidation resistance and damage tolerance. Inconel 625 and 718 have potential application in jet engines and gas turbines components. On the other hand, Fe-based alloys have some limitations through AM fabrication as the density of AM processed steels isn't the same as the full one. The main reason behind this limitation is the special chemical properties of the main elements in steels, but a lot of concern is given for more development. Different AM processes to fabricate multicomponents of metallic alloys are given in Table 3 [23-26]. SMD has great advantages in shaping those types of alloys as it depends on creating near-net shaped components by utilizing tungsten inert gas welding. Large columnar prior $\beta$ grains with a wid-martensite $\alpha / \beta$ microstructure have been observed at Ti-6Al-4V the dense SMD components. It is obtained that the ultimate tensile strength depends on the orientation and location of the tensile specimens and it varied between 929 and $1014 \mathrm{MPa}$. It is observed too that strain failure percentage is $16 \pm 3 \%$ in case of tensile testing vertically to the deposition layers and about $9 \%$ in case of testing parallel to the layers. Ti-6Al-4V SMD components with different can be created with 5 and $20 \mathrm{~mm}$ and fine $\alpha$ lamellae can be found in the top region and coarse one can be found in the bottom region. In comparison with cast material and components built by other additive manufacturing techniques, Ti-6Al-4V SMD is more competitive in term of mechanical properties [27]. Ti alloys are considered as difficult to cut or shape and machining processes of those alloys are very expensive by tradition methods [28]. Applications of AM technology on Al alloys are considered as a big challenge, especially in laser processing with high reflectivity to laser energy. A number of AM proposed aluminum alloys were discussed and analyzed. For example, AM proposed AlSi10Mg alloy are investigated using selective laser melting (particular powder-bed process (to study different performance characteristics such as; high cycle fatigue, fracture behavior, and the microstructure. 91 sample have been used in different directions $\left(0,45^{\circ}, 90^{\circ}\right.$ (and in different heating effect $\left(30^{\circ} \mathrm{C}, 300{ }^{\circ} \mathrm{C}\right)$. Statistical analysis (design of experiments) and marginal means plots were used to analyze the data results. It is obtained that the post heat treatment is most signification variable while building direction isn't more significant during studying of the fatigue resistance. The optimal setting was $300^{\circ} \mathrm{C}$ platform heating and peakhardening to neutralize the differences in fatigue life and increase the fatigue resistance. Cellular dendrites of $\alpha-\mathrm{Al}$ and interdendritic Si particles are used to characterize The as-built microstructure, however, no difference have been noticed between $0^{\circ}, 45^{\circ}$, and $90^{\circ}$ and the microstructure are homogeneous, dendrites, laser traces, and heat affected zones dissolved, and Si particles formed to a globular shape. In term of fracture behavior, the breakthrough cracks start from the surface or subsurface and non-melted spots and pores are observed [29].

Laser additive manufacturing is one of the effective processes which depend on the calculating cooling rate and peak temperature (numerical simulation). AISI 1030 carbon steel with $\mathrm{Fe}-\mathrm{TiC}$ composite coating is used to study the process parameters effects values on the $\mathrm{TiC}$ morphology and microstructure. It has been investigated that cooling rate has an effective role in the morphology and microstructure as a rejection of solute material to the molten $\mathrm{Fe}$ is retarded when the cooling rate is increased above than $1500 \mathrm{~K} / \mathrm{s}$. On the other hand, in order to achieve the desired microstructure, the cooling rate, melt pool and dilution characteristics are very important to be optimized. Furthermore, uniformity of the particles distribution (Tic), low laser power provides excellent hardness results and makes laser additive manufacturing is more applicable for different applications [30, 31]. Selective laser melting using a pulsed-laser source has a new approach

Table 3. Multi-components of metallic alloys and AM fabrication processes.

\begin{tabular}{|c|c|c|c|c|}
\hline Alloy & Compositions & Processes & Laser Type & Properties \\
\hline Ti-based & $\mathrm{Ti}-6 \mathrm{Al}-4 \mathrm{~V}$ & DMD & $\begin{array}{l}\mathrm{CO}_{2} \text { laser, } \\
6 \mathrm{KW}\end{array}$ & $\begin{array}{l}\text { Tensile strength } 1163 \pm 22 \mathrm{MPa} \text {, yield strength } 1105 \pm 19 \mathrm{MPa} \text {, } \\
\text { ductility } 4 \% \text { (as deposited); tensile strength } 1045 \pm 16 \mathrm{MPa} \text {, yield } \\
\text { strength } 959 \pm 12 \mathrm{MPa} \text {, ductility } 10.5 \pm 1 \%\left(950{ }^{\circ} \mathrm{C} \text { annealed }\right)\end{array}$ \\
\hline Ti-based & Ti-6Al-4V & LM & $\begin{array}{l}\text { Ytterbium fiber } \\
\text { laser, } 200 \mathrm{~W}\end{array}$ & Approximately $100 \%$ density; tensile strength $>1000 \mathrm{MPa}$ \\
\hline Ti-based & Ti-6Al-4V & LMD & Nd: YAG laser & Tensile strength $1211 \pm 31 \mathrm{MPa}$; yield strength $1100 \pm 12 \mathrm{MPa}$ \\
\hline Ni-based & $\begin{array}{c}\text { Inconel } 625(\mathrm{Ni}-22 \mathrm{Cr}-5 \mathrm{Fe}- \\
3.5 \mathrm{Nb}-9 \mathrm{Mo}-0.4 \mathrm{Al}-0.4 \mathrm{Ti}-0.1 \mathrm{C})\end{array}$ & LM & $\begin{array}{l}\text { Continuous } \\
\text { wave fiber laser }\end{array}$ & $\begin{array}{l}\text { Ultimate tensile strength } 1030 \pm 50 \mathrm{MPa} \text { (horizontal) } \\
\text { and } 1070 \pm 60 \mathrm{MPa} \text { (vertical); } 0.2 \% \text { yield strength } 800 \pm 20 \mathrm{MPa} \\
\text { (horizontal) and } 720 \pm 30 \mathrm{MPa} \text { (vertical); Young's modulus } \\
204.24 \pm 4.12 \mathrm{MPa} \text { (horizontal) and } 140.66 \pm 8.67 \mathrm{MPa} \\
\text { (vertical); elongation about } 8-10 \%\end{array}$ \\
\hline Ni-based & $\begin{array}{l}\text { Inconel } 718(\mathrm{Ni}-19 \mathrm{Cr}-18 \mathrm{Fe}- \\
0.5 \mathrm{Al}-1 \mathrm{Ti} 3 \mathrm{Mo}-5 \mathrm{Nb}-0.042 \mathrm{C})\end{array}$ & LMD & $\begin{array}{l}\text { Continuous } \\
\text { wave } \mathrm{CO}_{2} \text { laser, } \\
5 \mathrm{KW}\end{array}$ & $\begin{array}{l}\text { Tensile strength } 845 \mathrm{MPa} \text { (as deposited) and } 1240 \mathrm{MPa} \\
\text { (heat treated); } 0.2 \% \text { yield strength } 590 \mathrm{MPa} \text { (as deposited) and } \\
1133 \mathrm{MPa} \text { (heat treated); elongation } 11 \% \text { and reduction } \\
\text { in area } 26 \%\end{array}$ \\
\hline Fe-based & Stainless steel Inox 904L & LM & $\begin{array}{l}\text { Continuous } \\
\text { wave fiber laser }\end{array}$ & $\begin{array}{l}\text { Successful fabrication of } 20 \times 20 \times 5 \mathrm{~mm} \text { object with } \\
140 \mu \mathrm{m} \text { thick inner compartment wall }\end{array}$ \\
\hline Fe-based & High-speed steel M2 & LS & $\begin{array}{l}\text { Continuous } \\
\text { wave } \mathrm{CO}_{2} \text { laser }\end{array}$ & Maximum density $88.2 \%$ \\
\hline
\end{tabular}



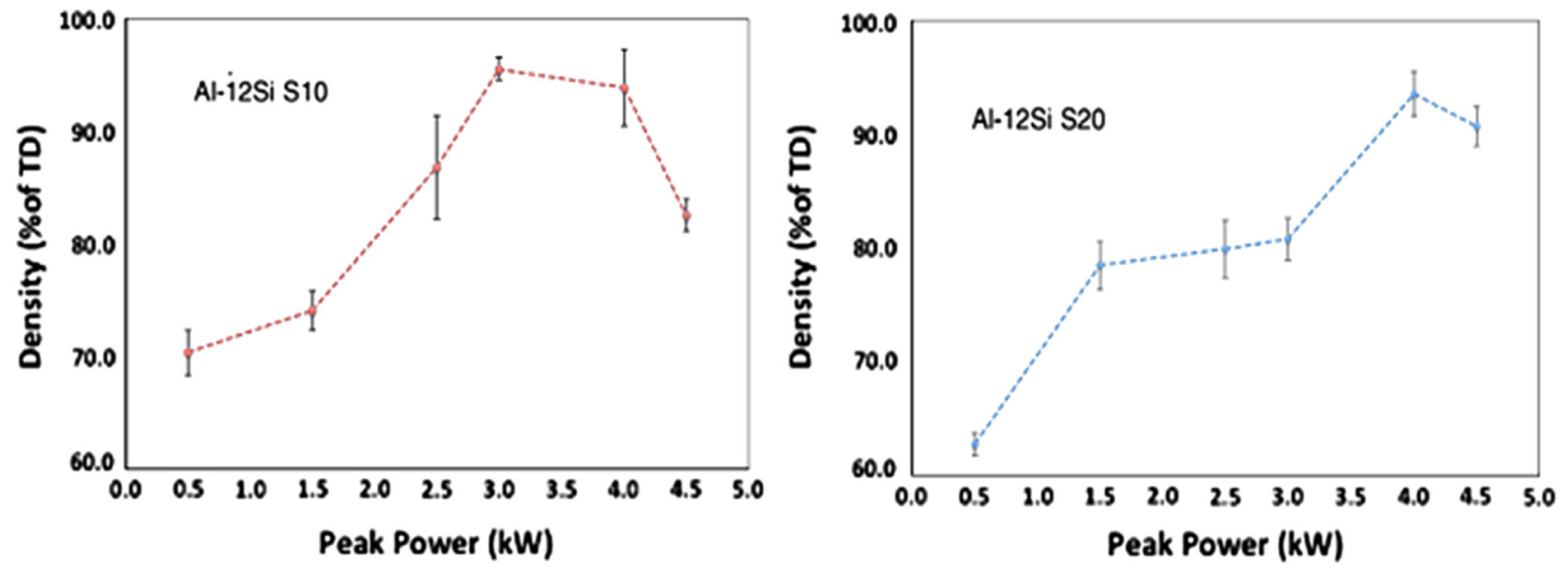

Figure 5. The effect of peak power on the density for Al-12Si S10 and Al-12Si S20.

to be applied on Al-12Si alloy and this approach allows to sufficient control over the heat input and effective microstructure optimization. The hardness of above $135 \mathrm{HV}$, density up to $95 \%$ and $\mathrm{Si}$ refinement below $200 \mathrm{~nm}$ were obtained. The effect of peak power on the density for two different particles sizes (Al-12Si S10 and Al-12Si S20) is given in Figure 5, while CT scan images of the SLM-S10 specimen are given in Figure 6. It is concluded that an increase in hardness is observed in comparison with cast alloy and other SLM studies and the morphology of microstructure depends on thermal gradients and large undercooling [32].

\subsection{Ceramic matrix composites and ceramic components}

It is obtained that fabrication of ceramic matrix composite is difficult by using conventional techniques. On the other hand, AM technology has the ability to deal with those type of materials without the need for molds or part specific tools. The most common processes used for producing ceramic components, in general, are three-dimensional printing, selective laser sintering, stereolithography, and direct inkjet printing $[33,34]$. Selective laser gelation (SLG) has been used to fabricate one of ceramic matrix composites which consist of stainless steel powder and a silica sol at a proportion of 65-35 wt.\%. The gelled silica matrix with embedded metal particles was used to form 3D composite part and distributed over the silica gelled layer using Nd: YAG laser technique. The advantage of this processing approach is an optimal saving of laser-forming energy (low the better) and fabrication speed (higher the better). Experimental rapid prototyping machine has been used to create smallest layer thickness with $50 \mu \mathrm{m}$ through carrying out series of experiments $[35,36]$. Selective laser gelation (SLG) has been used to fabricate one of ceramic matrix composites which consist of stainless steel powder and a silica sol at a proportion of 65-35 wt.\%. The gelled silica matrix with embedded metal particles was used to form 3D composite part and distributed over the silica gelled layer using Nd: YAG laser technique. The advantage of this processing
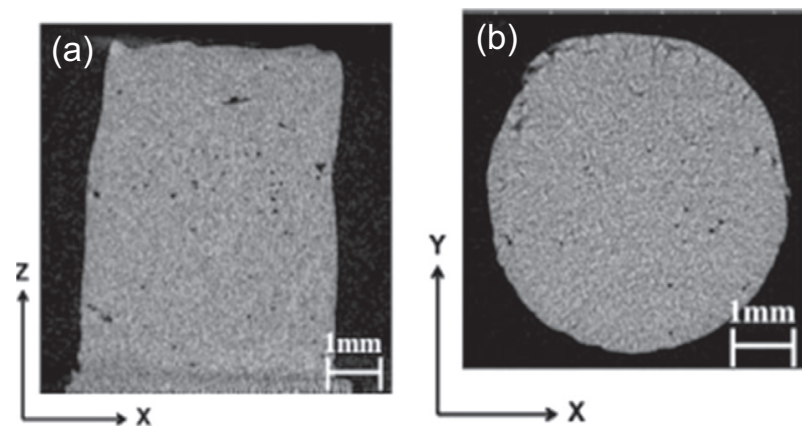

Figure 6. CT scan images of SLM-S10.

approach is an optimal saving of laser-forming energy (low the better) and fabrication speed (higher the better). Experimental rapid prototyping machine has been used to create smallest layer thickness with $50 \mu \mathrm{m}$ through carrying out series of experiments. Under a laser energy density of $0.4 \mathrm{~J} / \mathrm{mm}^{2}$, the performance responses were observed as; a surface finish of $32 \mu \mathrm{m}$, a bending strength of $45 \mathrm{MPa}$ and a dimensional variation of $10 \%$. It is confirmed during this study that SLG requires less forming energy than SLS through the fabrication of metal/ceramic components. Schematic of the experimental setup is given in Figure 7 and examples of CMC parts using SLG are given in Figure 8 [35-37]. AM technology was used to fabricate and develop fully dense ceramic freeform-components through high-strength oxide ceramics $\left(\mathrm{ZrO}_{2}-\mathrm{Al}_{2} \mathrm{O}_{3}\right.$ ceramic) with improved mechanical properties. Complete melting of $\mathrm{ZrO}_{2}-\mathrm{Al}_{2} \mathrm{O}_{3}$ by using laser beam (SLM) has been obtained experimentally. 100\% density and $500 \mathrm{MPa}$ of flexural strength have been observed without any sintering processes or any post-processing crack-free specimens. In term of the microstructure, two fine-grained phase microstructure consisting of tetragonal zirconia and alpha-alumina were manufactured. This processing proves some significant advantages compared to laser sintering techniques and it has a lot of applications such as; dental restorations and ceramic prototypes with complex shapes. However 


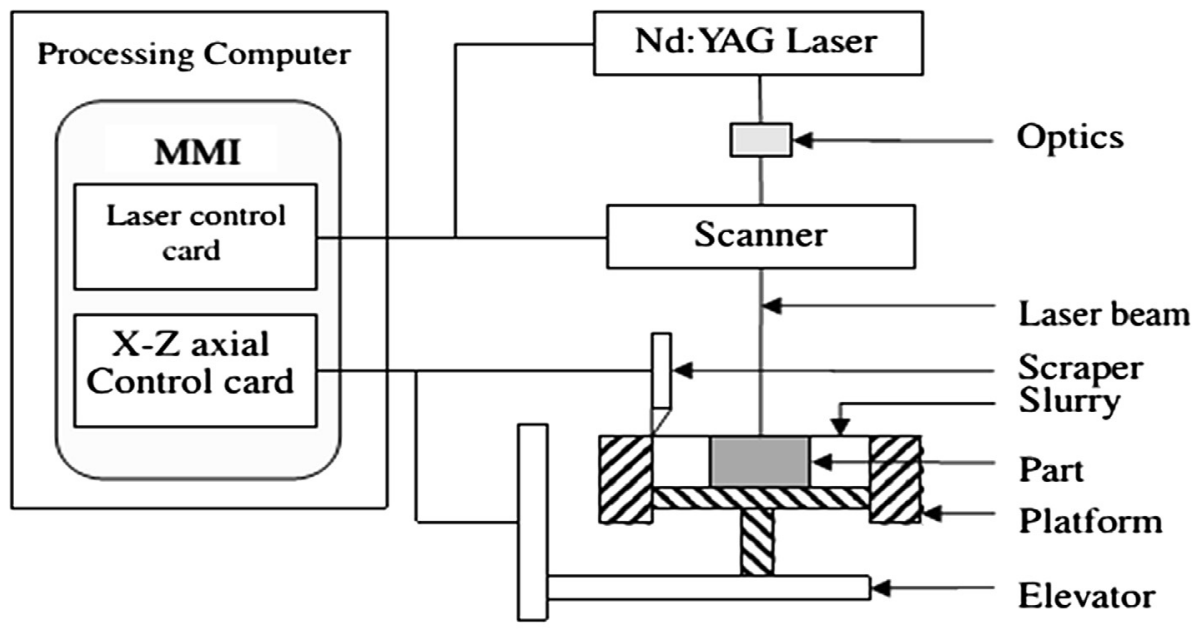

Figure 7. SLG experimental setup.

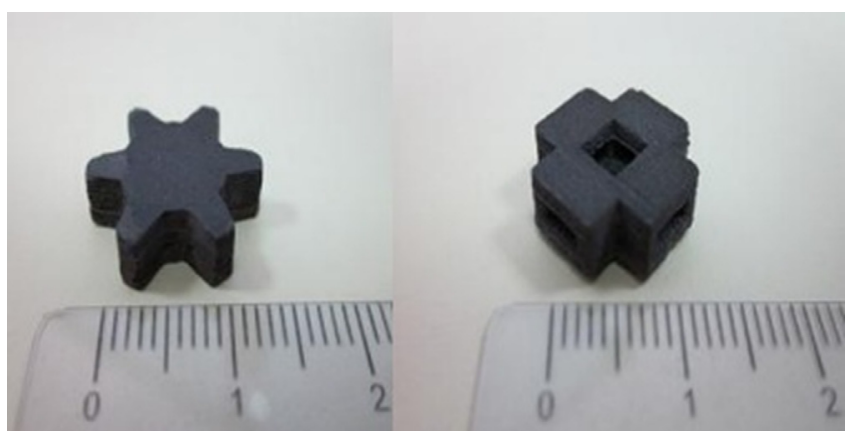

Figure 8. CMC parts using SLG.

all those advantages, there are some limitations in the surface quality of manufactured component and the mechanical strength [38].

A number of ceramic suspensions such as; $3 \mathrm{Y}-\mathrm{TZP}, \mathrm{Al}_{2} \mathrm{O}_{3}$, and ZTA (oxide) or $\mathrm{Si}_{3} \mathrm{~N}_{4}$ and $\mathrm{MoSi}_{2}$ (non-oxide) have been studied using direct inkjet printing (DIP) to investigate processing possibilities through microstructures, laminates, threedimensional specimens, and dispersion ceramics. This process was modified by using aqueous ceramic suspensions of high solids content instead of the ink. The main significant parameters have been investigated as; solids content, viscosity and surface tension. It is obtained that wall thicknesses of about $200 \mu \mathrm{m}$ can be achieved using proposed DIP. Good bonding between layers of the same material was observed in processing of $\mathrm{ZrO} 2$ and for different materials as well (ZTA/3Y-TZP). Structural and functional parts by layer-wise build-up via DIP were produced using aqueous inks of $\mathrm{Si}_{3} \mathrm{~N}_{4}$ and $\mathrm{MoSi}_{2}$ with high solids content and excellent mechanical characteristics were noticed. It is concluded that optimization of the process technology and material parameters are recommended to create fast, reliable and flexible production of complex-shaped non-oxide ceramic parts. Samples of developed box with two movable matches (I) and printed and sintered channel structures (II) of 3Y-TZP are given in Figure 9 [39, 40]. Nowadays, a new technique of AM technology processes for dense and strong ceramic components is investigated. This technique is called lithography-based ceramic manufacturing (LCM) and it is considered as a dynamic mask exposure process based on the selective curing of photosensitive slurry. LCM (CeraFab 7500 system) has been applied for fabrication of strong, dense and accurate alumina ceramics. No geometrical limitation has been observed and it is investigated that over $99.3 \%$ of a theoretical alumina density was achieved. Furthermore, bending strength of $427 \mathrm{MPa}$ was obtained based on four points and very smooth surfaces was created. In terms of mechanical properties, the new techniques offers equivalent to ceramic materials structured by conventional processes. It is concluded that this technique can be used for small lot sizes or customized ceramic parts with very complex geometries and delicate features [41].

\subsection{Polymer matrix composites}

AM technology has an impact in processing effective and potential polymer composites such as; carbon fiber-polymer composites as it has the ability to handle complex shapes with great design flexibility. Short fiber $(0.2-0.4 \mathrm{~mm})$ reinforced acrylonitrile-butadiene-styrene (ABS) composites was fabricated using 3D-printing and the processing has been analyzed through different responses such as; mechanical properties performance, microstructure, and processability itself. In comparison with traditional compression molded composites, 3Dprinted samples achieved higher percentages of increase around $115 \%, 700 \%, 91.5 \%$ for the tensile strength, tensile modulus and yielding respectively. Fiber orientation, dispersion, and void formation were used to analyze the microstructure and mechanical performance effects. Despite previous advantages, high porosity is observed in 3D-printed composites as compared with traditional techniques. Furthermore, it noticed that average and long fiber length have provided less performance because of the high-shear mixing step during compounding as shown in Figure 10. It is concluded that the use of carbon fiber-reinforced feedstock with optimized 

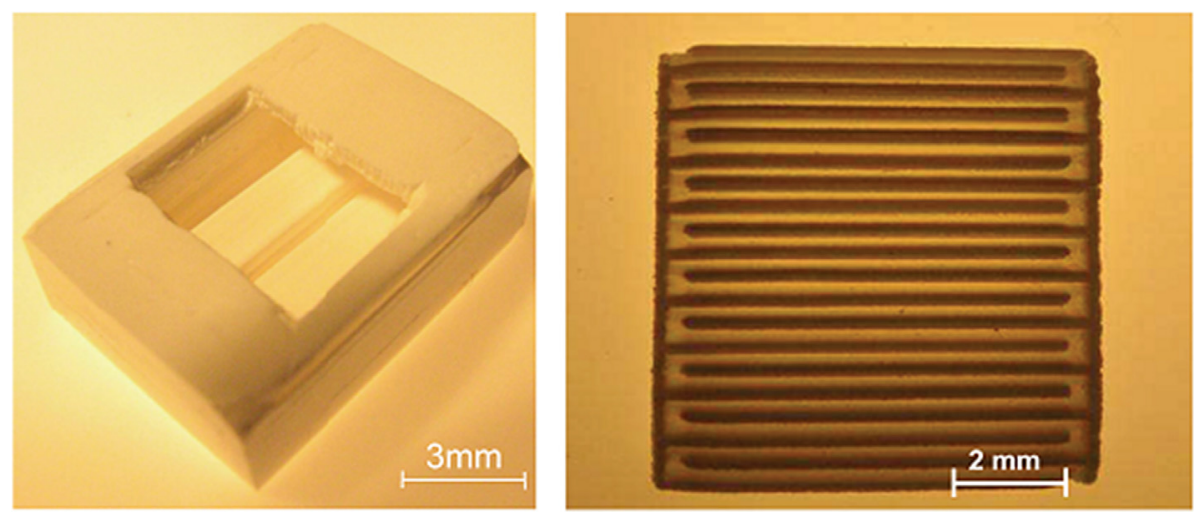

Figure 9. 3Y-TZP samples.

(a)

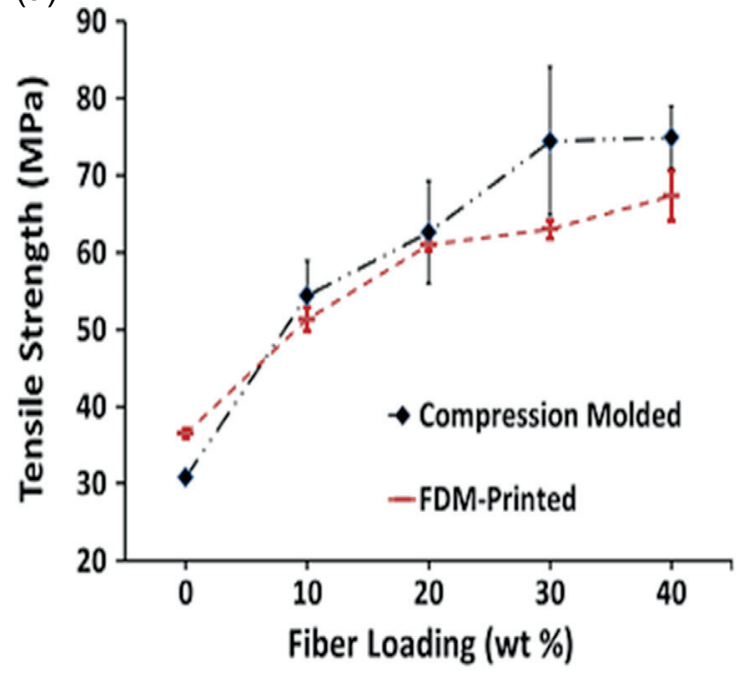

(b)

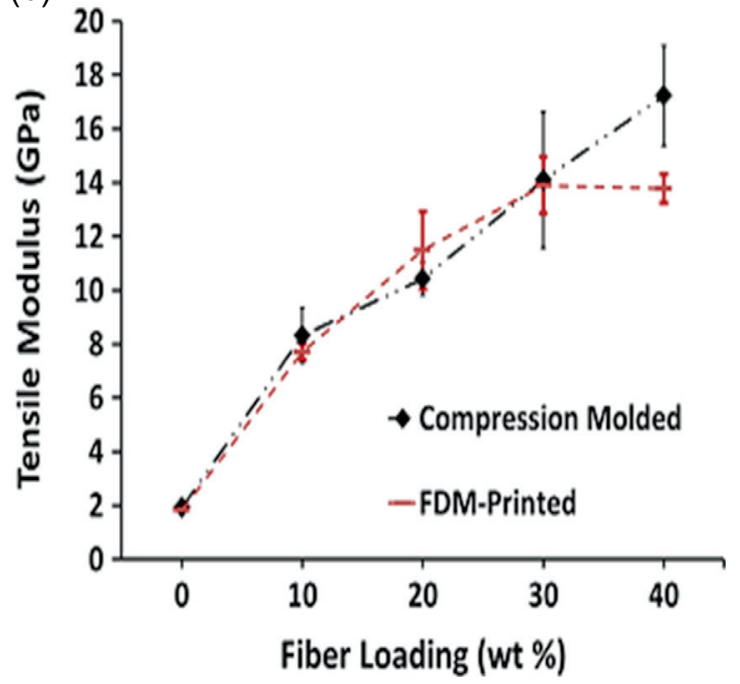

Figure 10. Fiber loading (wt.\%) versus tensile strength for ABS [42].

orientation, good dispersion capabilities and improving interfacial adhesion between fibers and matrix via surface modification has an impact advantage in the industry of load-bearing composite parts [42].

There is list of barriers limit the widespread adoption of AM technology of polymer composites such as $[43,44]$ :

I. extremely low production rate;

II. the small physical size of the parts;

III. the mechanical properties limitations.

On the other hand and especially for carbon fibers, more developed ways are obtained to solve these barriers. Some of the proposed techniques are as follows [44]:

I. In term of improving specific strength developed carbon-fiber-reinforced polymers are used.

II. Decreasing the distortion and warping of the material during deposition by using carbon fiber additions which provide a high deposition rate manufacturing.
III. The integration between carbon fiber and AM technologies has an important advantage of creating complex components that would not be possible with either technology alone.

On the other hand, quasicrystalline polymers have a high commercialization impact of development polymer composites through AM technology. It is investigated that SLS process was used to study the characteristics of proposed material in comparison with hard steel. The responses measured for this comparative study were porosity, hardness, wear resistance and friction coefficient. Generally, quasicrystalline polymer composites offered definite advantage which leads this type of material to have an effective participation in the automotive industry [45].

\subsection{Nano-composites}

It is investigated that more concern is required to fabricate composite materials in one process cycle which provides 

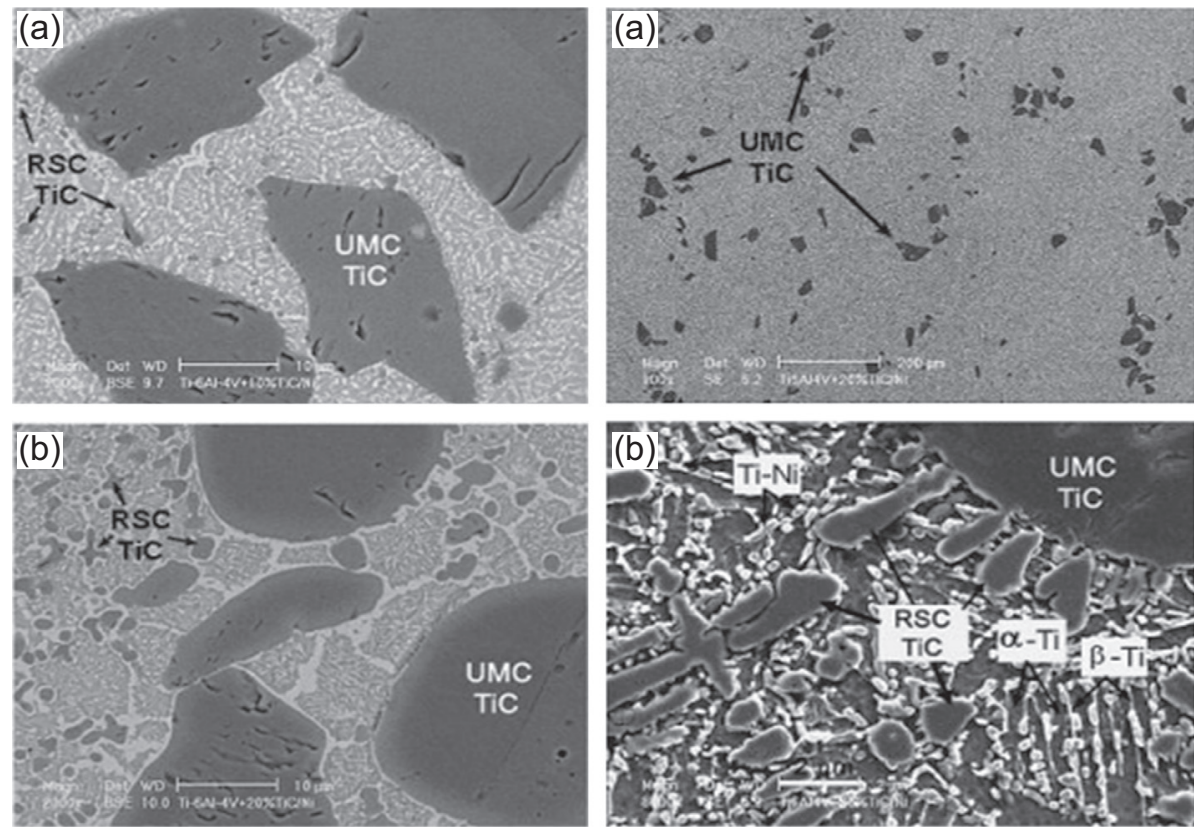

Figure 11. Ti6Al4V with 10 wt.\% and 20 wt.\% TiC/Ni micrographs (SEM).

sufficient material characteristics without any creating, reconditioning and treatment of the bulk material. One possibility of the additive technologies to achieve the previous requirement is using nano-size structures of constructional materials. It is obtained that $3 \mathrm{D}$ composite structures based on nanomaterials have a number of potential applications in temperature drop operations and aggressive chemical or biological environments applications. On the other hand, SLS is considered as very efficient process create metal composites functional parts with less labor effort, shorter time and the ability for complex or internal cavities geometry [46, 47]. Another nano-composite application through AM is discussed. The fabrication of nanocrystalline titanium carbide (TiC)-reinforced with Inconel 718 matrix bulk-form using SLM process was investigated. The effect of SLM process variables has been used to study the microstructure, general properties of the fabricated part, and metallurgical mechanisms. Due to the formation of either larger-sized pore chains or interlayer micro-pores within insufficient laser energy density, the densification response was limited. magnification micrograph for LENSdeposited Ti6Al4V $+20 \mathrm{wt} . \% \mathrm{TiC} / \mathrm{Ni}$ is given in Figure $11 \mathrm{~b}$ respectively [48]. In term of ceramic nanocomposites, high solid content and stable processing conditions are prerequisites of ceramic production technology. Thermo-kinetic deposition processes and spray-drying are new additive techniques used to include nano-ceramic coatings which help to achieve the perquisites requirements and offering favorable rheological properties [49]. A wider material selection and flexible design can be achieved using additive nano-manufacturing (ANM) is given as shown in Figure 12. Examples of ANM technologies are dip-pen lithography (DPN), electro-hydro-dynamic jet printing (EHD), optical tweezers and electro-kinetic nanomanipulation, and direct laser writing (DLM). The most significant ANM process variables are minimum feature size

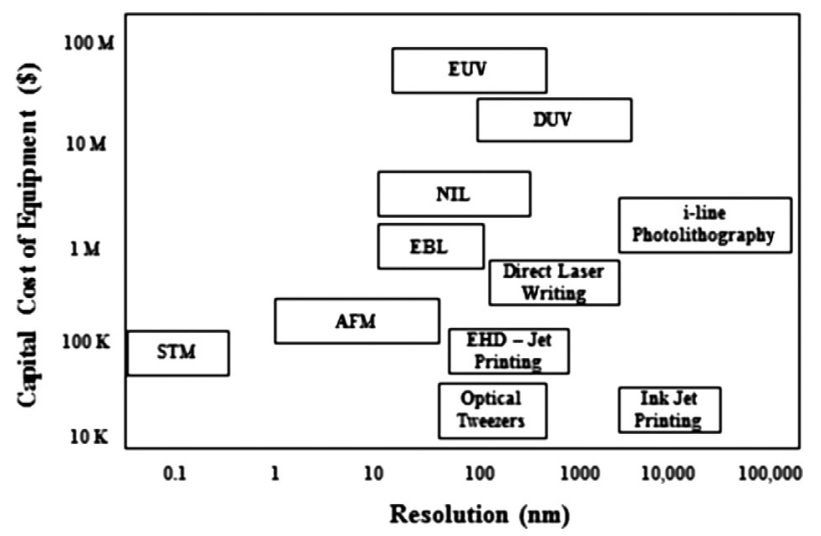

Figure 12. Resolution versus capital cost of equipment (\$) of ANM [50].

(resolution), deposition speed and material selection. Comparison between different ANM technologies features have been investigated and shown as in Table 4 [50-53]. It is concluded that mechanical properties, thermal and electric conductivity, sintering temperatures, dimensional accuracy of nanocomposites through AM technology can be improved, but there are still a number of barriers in each AM method such as; aggregation within printing media, the rough surface finish of printed parts and nozzle clogging. By other meaning, standardise process parameters and synthesis methods for different nanomaterials and processes don't exist by sufficient way till now [54]. One of nanocomposite components through AM technology was the manufacturing of TiC/Ti nanocomposite parts using SLS. The laser process parameters effects besides the nano-powder type were used to study different responses such as; the microstructure features, the densification behavior and the tribological properties of the SLM-processed TiC/Ti. 
Table 4. Comparison between different ANM technologies features.

\begin{tabular}{llcc}
\hline Method & \multicolumn{1}{c}{ Material } & Speed & Resolution \\
\hline DPN & From small organic molecules to organic and biological & Increased with the & $15 \mathrm{~nm}$ resolution on single crystal surfaces, \\
& polymers and from colloidal particles to metal ions and sols & number of probes & 50 nm on polycrystalline surfaces \\
EHD & Metal nano-particles, polymers, block copolymers & $80 \mathrm{~mm} / \mathrm{s}$ & $10 \mathrm{~nm}$ \\
DLW & Polymers, metals & $100 \mu \mathrm{m} / \mathrm{s}$ & $65 \mathrm{~nm}, 22 \mathrm{~nm}$ \\
STM & Single atoms (e.g., Xe) & $<1 \mathrm{~nm} / \mathrm{s}$ & Atomic \\
AFM & Single atoms (e.g., Sn), any nano-scale object & $<10 \mathrm{~nm} / \mathrm{s}$ & Atomic \\
& (e.g., CNTs, nano-particles) & & \\
\hline
\end{tabular}

Directly mechanically mixed nano-TiC/Ti powder and ballmilled $\mathrm{TiC} / \mathrm{Ti}$ nanocomposite powder were applied. It was concluded that the laser energy density and powder categories are the most significant variables which affect the densification. The optimal laser energy was $0.33 \mathrm{~kJ} / \mathrm{m}$ while the ball-milled TiC/Ti nanocomposite powder gave higher SLM densification. In term of microstructure, the lamellar nanostructure of the TiC reinforcement has been found. It can be the same as nanoparticle morphology before SLM with an adjusted range of laser energy densities, but it can be relatively coarsened microstructure because the process sensitivity SLM parameters, and the $\mathrm{TiC}$ reinforcement. Low coefficients of friction of 0.22 and wear rate of $2.8 \times 10^{-6} \mathrm{~m}^{3} \mathrm{~N}^{-1} \mathrm{~m}^{3}$ were achieved with higher laser energy density. The relationship between laser energy versus relative density and coefficient of friction are given in Figure 13 [55].

\subsection{Structural composites}

$\mathrm{CAD} / \mathrm{CAM}$-based layered manufacturing has been used to investigate the EBM process technique for fabrication of porous titanium periodic cellular structures (medical grade substitutions) which have different applications in biomedical field. According to the requirements of loading conditions of real-time use, the mechanical properties of the cellular titanium structures were considered very suitable for use in biomedical applications. Composite sandwich functionally graded structures were fabricated using simultaneous powder and wire feeding laser deposition in a single step to investigate the feasibility and performance characteristics. Materials used in this study were copper powder and nickel wire to deposit functionally copper/nickel/iron structures on $\mathrm{H} 13$ tool steel. In terms of morphology, composition distributions, microstructures (phases formed), different experimental devices were used such as; Electron probe microanalysis (EPMA), scanning electron microscopy (SEM), energy dispersive X-ray spectroscopy (EDS), X-ray diffraction (XRD) and optical microscopy. Functionally graded $\mathrm{Cu}-\mathrm{Ni}-\mathrm{Fe}$ structures have achieved successful deposition and processing was verified using dual powder feed deposition process which has a problem in the inclusion of un-melted $\mathrm{Ni}$ powders in the $\mathrm{Cu}$ layer [56]. Another important developed concept is compositionally graded metals. Laser deposition process has an important advantage by creating a melt pool in the wake of the laser which made it very suitable to perform layer by layer alloying. This feature allowed making separated composition characteristics for each single layer. Traditional techniques depend on two ways; localized heat treating or surface engineering, but using LD allows for the freeform hardware through computer models to be changed and adjusted and this leads to control of internal structure composition. This investigation helps more in metallic metallurgy and alloy development studies. Build head illustration during LD process and schematics of one compositionally graded alloy are given in Figure 14. Functionally graded material (FGM) offers the ability to control the composition and optimize the properties of the built part. FGM have a lot of potential application fields. Potential examples of FGM are; graded thermoelectrics and dielectrics piezo-electrically graded materials, graded composite electrodes and tungsten-copper composites. Metal or metalceramic FGM can be manufactured using SLM technique, laminated Object Manufacturing, laser cladding, or ultrasonic consolidation. On the other hand, polymer-polymer or polymer-ceramic, ceramic-ceramic can be fabricated using inkjet printing, SLS, or 3D printing [57-59].

One of the used techniques to build up functionally graded fully dense structures is Laser deposition of injected powders with varying compositions (layer by layer). FGM based on nanocomposites has an effective potential as well. It is obtained that 3D structure in functionally graded polymer nanocomposites have been constructed using SLS layered manufacturing-based freeform fabrication. In this work, Nylon-11/silica nanocomposite was fabricated using different volume fraction of $15 \mathrm{~nm}$ fumed silica nano-particles which varied from $0-10 \%$. The processing variables are part substrate temperature set point, roller speed, laser power and scan speed. Resulting density was measured each time and design of experiments (DOE) was used to analyze the results. Optical microscopy and transmission electron microscopy (TEM) have been used to investigate the proposed micro/nanostructures of the nanocomposites. The optimized processing parameters gave sufficient sequence for fabrication and average relative resulting density was $99.7 \%$. Finally, it is concluded that threedimensional functionally graded polymer nanocomposites can be produced using SLS by the same concept onedimensional composition gradient, but spatially varying mechanical properties can occur [60]. Another FGM study has been concerned with using spark plasma sintering (SPS) to produce $\mathrm{ZrB}_{2}-\mathrm{SiC} / \mathrm{ZrO}_{2}$ (3Y) FGM. It was noticed that temperature gradient sintering can be increased using pre-designed graphite die with special outline dimensional control. The composition distribution and hardness of SPS-sintered FGM were used to evaluate the process performance. Toughening and reinforcing the individually graded layers are observed due to 

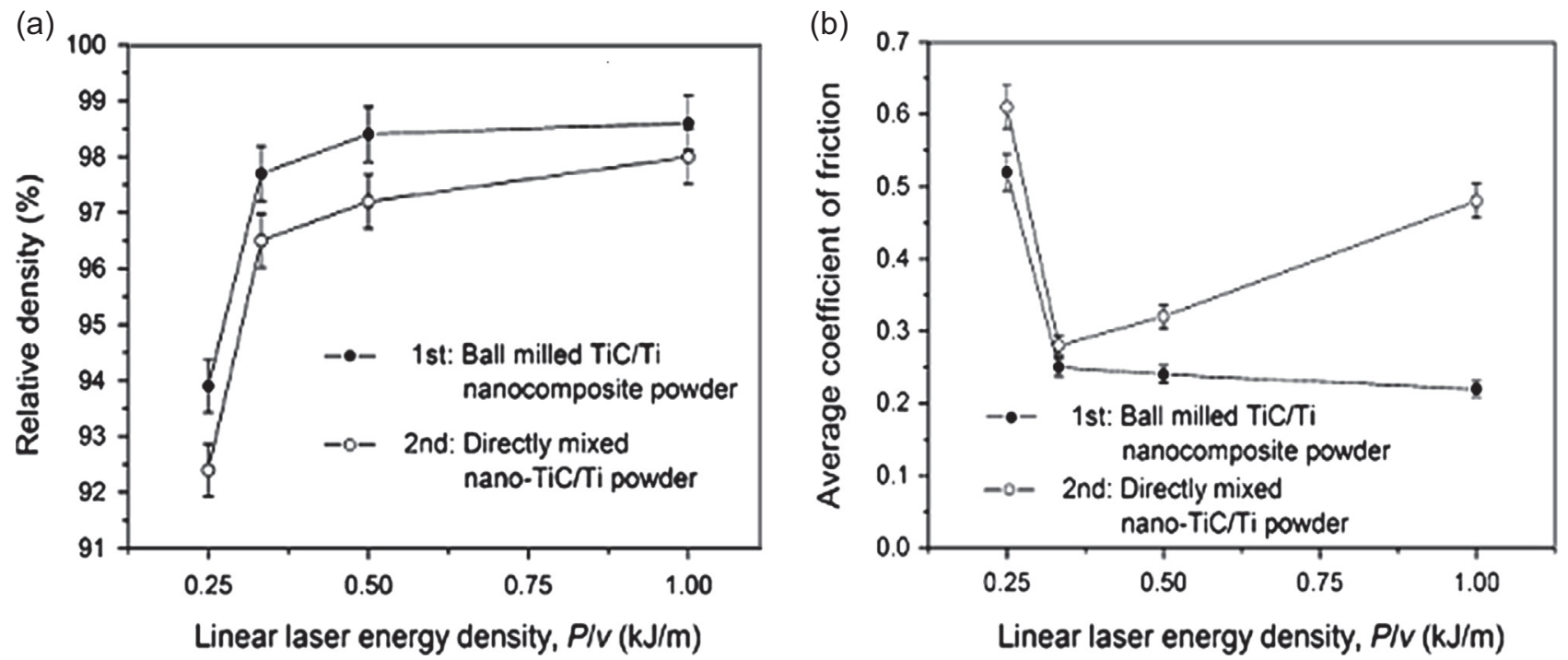

Figure 13. Laser energy versus relative density and coefficient of friction of TiC/Ti nano-composite [55].
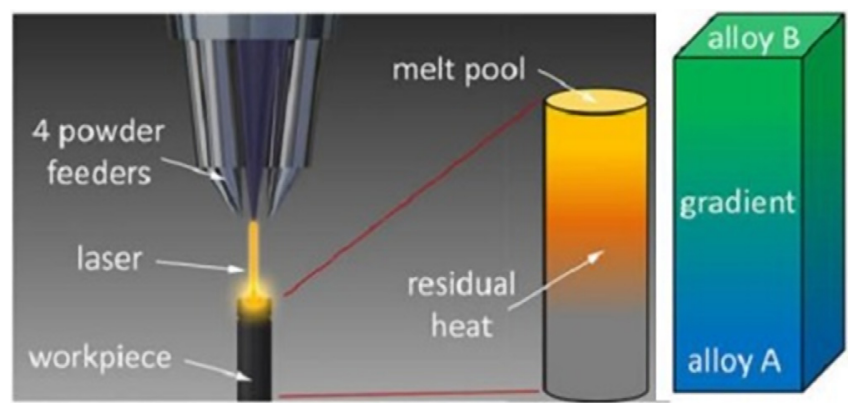

Figure 14. Build head illustration during LD process and schematics of one compositionally graded alloy.

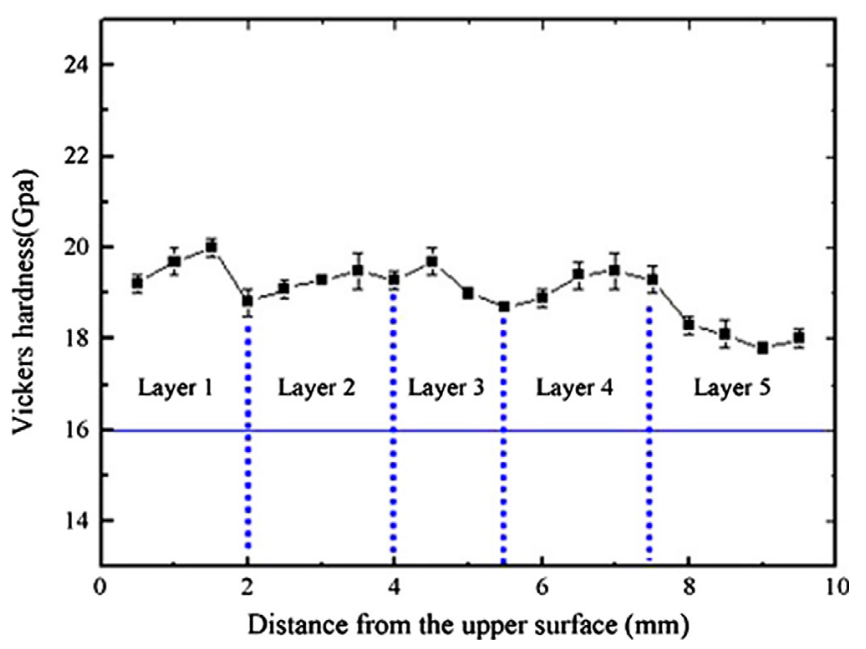

Figure 15. The hardness variation of $\mathrm{SiC} / \mathrm{ZrO}_{2}(3 \mathrm{Y})$ FGM [73].

existing of partially stabilized $\mathrm{ZrO}_{2}$ with a gradient composition distribution in the FGM. In comparison with the density measured in a freestanding specimen, it is noticed that the fabricated

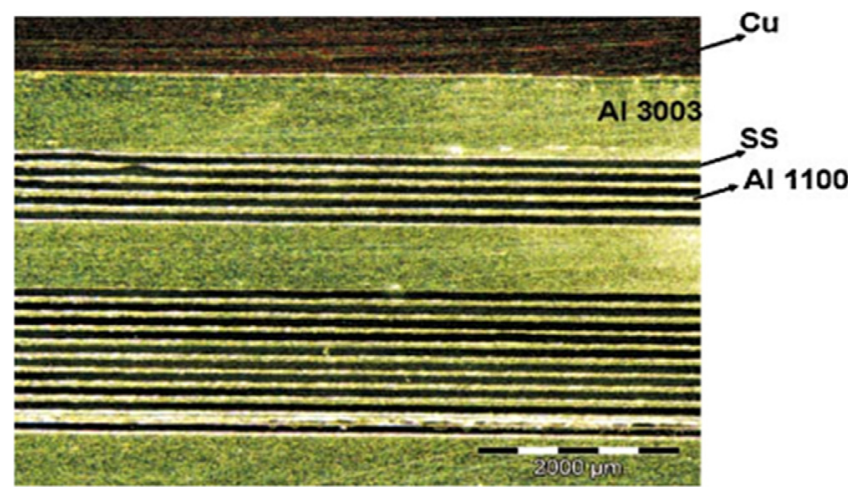

Figure 16. Micrograph of fabricated FGM sample using UC.

part density was identical. The hardness values varied from 17.8 to $19.2 \mathrm{GPa}$ and the slight decrease is noticed in on the boundaries between adjoining composition layers as shown in Figure 15. It is obtained an increase of the fracture toughness from the upper surface to the bottom surface because of the phase transformation of $\mathrm{t}-\mathrm{ZrO}_{2}$ to $\mathrm{m}-\mathrm{ZrO}_{2}$ during fracture [61]. One of FGM studies focused on joining of stainless steel, $\mathrm{Al}$ and $\mathrm{Cu}$ foils using ultrasonic consolidation (UC) technique. Optimized layer sequence has been adopted and the optimum sample has been found as 62 foils of width $2^{\prime \prime}$ and length $13^{\prime \prime}$. Optical microscopy graph has proved the successful fabrication of the FGM using UC. Micrograph of fabricated FGM sample is given in Figure 16. The final recommendation in this study to improve the FGM fabrication process using UC was adopting the machining strategy or using an intermediate glue layer [13]. Structures with different dense and porous of titanium powder have been fabricated using EBM metal processing and it has satisfied the esthetic and functional requirements of the patient and the surgical community [62].

Non-uniform rational B-spline and FGM based features have been used in developing adaptive rapid 

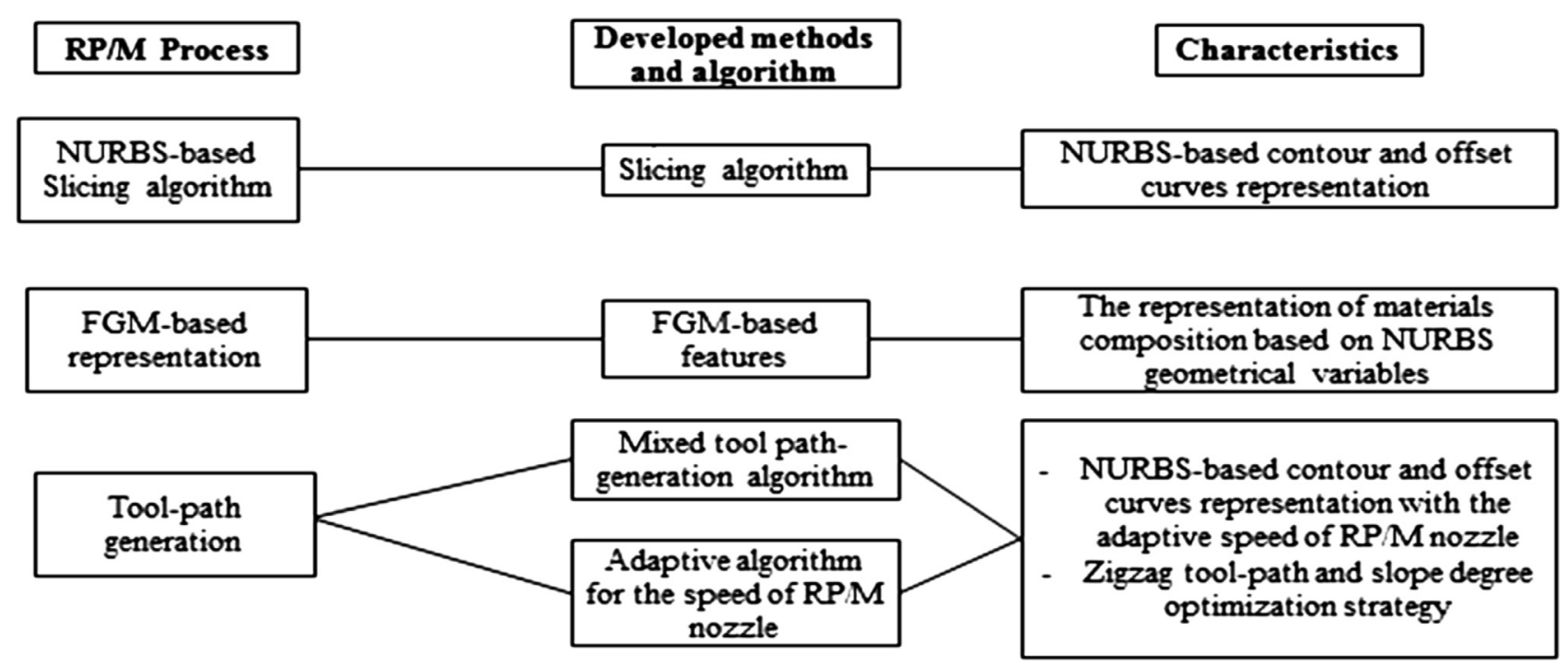

Figure 17. Non-uniform rational B-spline and FGM optimization algorithm.

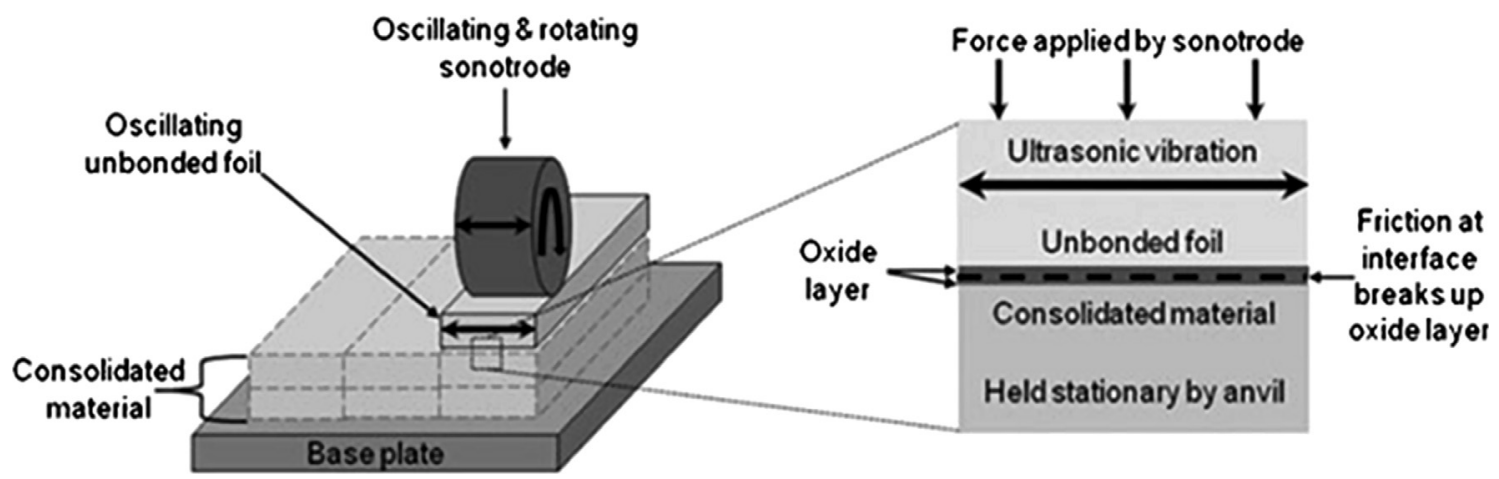

Figure 18. Schematic of UAM process some illustrations and characteristics of RP/M are given in Table 6 [63, 67-70].

prototyping/manufacturing (RP/M) algorithms for functionally graded material (FGM)-based biomedical models. The tool path optimization algorithm is given in Figure 17. To demonstrate the performance of this work in terms of algorithm effectiveness, case studies of FGM-based biomedical models have been applied. The most important results of this research are [63]:

I. Introducing NURBS to represent the contours of sliced layers of biomedical CAD models leads to maintain the geometrical accuracy of original biomedical CAD models.

II. Addressing the specific functional needs using he linear and non-linear control parameters for FGM composition and distributions.

III. Effectively optimize build time towards a minimum target can be achieved through The developed adaptive speed algorithms along the contour/offset and zigzag tool paths for RM nozzles/print.

Different industrial applications need sufficient design for Multiple-material engineering structure as it provides function-specific material members. It has been investigated that AM technology has a number of capabilities for fabrication of those types of composites such as; the ability to create complex geometries. Despite the previous capabilities, AM technologies for multi-material structure fabrication are still an ongoing area of research. There are number of potential applications of AM-fabricated multimaterial structures and some of them are as follows [64-66]:

I. Multi- polymer materials using 3D printing.

II. Multi-material scaffolds for tissue engineering applications using SL.

III. Multi-material metallic structures using laser powder deposition.

IV. Gradient structures such as; medical implant wear resistant surface coatings.

One of the structural composites studies focused on fabricating dual material engineering structures using ultrasonic additive manufacturing (UAM). Composite materials (Ti/Al 3003) and Al 3003 matrix material were used to 
Table 5. Mechanical and physical properties for the dual-material structure, Al 3003 and Ti/Al 3003.

\begin{tabular}{lcccc}
\hline Material & $\begin{array}{c}\text { Volume } \\
\text { fraction \% of } \\
\text { reinforcement }\end{array}$ & $\begin{array}{c}\text { Tensile } \\
\text { strength } \\
(\mathrm{MPa})\end{array}$ & $\begin{array}{c}\text { Stiffness } \\
(\mathrm{GPa})\end{array}$ & $\begin{array}{c}\text { Density } \\
\left(\mathrm{Kg} / \mathrm{m}^{3}\right)\end{array}$ \\
\hline $\mathrm{Al} \mathrm{3003}$ & - & 200 & 68 & 2730 \\
$\begin{array}{l}\text { Ti/Al 3003 } \\
\text { composite }\end{array}$ & 60 & 232 & 77.1 & 2934 \\
$\begin{array}{l}\text { The dual- } \\
\text { material }\end{array}$ & 25 & 500 & 129 & 3020 \\
\hline
\end{tabular}

create and design structure can carry compression and tension loads effectively. In comparison with Al 303 matrix, the dual-material structures proved that it can withstand higher loads than similar structures. Illustration of UAM process is provided in Figure 18, while some results of mechanical and physical properties between the 3 Al 3003, $\mathrm{Ti} / \mathrm{Al} 3003$ composite and the dual-material are given in Table 5 to indicate the potential of the dual-material structure [64].

\section{Opportunities, challenges, and future look}

In this section, AM technology is going to be discussed in terms of opportunities, challenges, and future look. AM technology has a lot of advantages and opportunities to develop and create a new smart path in different industry applications. Some of these opportunities have been investigated by different researchers as follows [71-73]:

I. Dealing effectively with structural composite materials by constructing or optimize material microstructure without changing the material's physical property.

II. The fabrication of continuous fiber- reinforced composites can be done sufficiently using SL and LOM process for mechanical applications.

III. Ceramics matrix composites can achieve higher properties using SLS and LENS.

IV. SLS can be used for fabrication polymers and polymers composites with sufficient mechanical properties.

V. Rapid prototyping has a lot of advantages over conventional techniques, especially for manufacturing of scaffolds using AM proposed bio-composites.

Table 6. Characteristics of RP/M.

\begin{tabular}{llll}
\hline $\begin{array}{l}\text { Technology of } \\
\text { manufacturing }\end{array}$ & FGM used & Process & Advantage $^{1}$ and disadvantage $^{2}$ \\
\hline Powder + binder +3 -DP & $\begin{array}{l}\text { Plaster powder }+ \text { multiple } \\
\text { binding fluids }\end{array}$ & $\begin{array}{l}\text { Local composition control (LCC) is } \\
\text { accompanied by a print head with several } \\
\text { jets, each depositing binders and/or slurries } \\
\text { of a material. The material composition is } \\
\text { on the scale of the binder droplets } 100 \mu \mathrm{m}\end{array}$ & $\begin{array}{l}\text { 1. Flexible in controlling composi- } \\
\text { tion and porosity, lower tempera- } \\
\text { involved, lower cost and } \\
\text { anechanical strength. }\end{array}$
\end{tabular}

Powder injection + laser Stainless steel AISI 316

melting

\section{$\mathrm{L}+$ stellite grade 12}

Powder + selective laser Hydroxyapatite and sintering

Filament + fused deposition modeling

Powder + selective laser sintering
Powders are injected on working zone by coaxial nozzles, controlled by CNC table, and then molten by $5 \mathrm{~kW} \mathrm{Nd:} \mathrm{YAG} \mathrm{laser}$ or $\mathrm{CO}_{2}$ laser. Layer thickness is $30-50 \mu \mathrm{m}$.

Hydroxyapatite and polyethylene are incorporated into an FGM-based matrix for bone implants. The average size of internal pores is $60-68 \mu \mathrm{m}$. The laser is a $10-\mathrm{W}$ $\mathrm{CO}_{2}$

Ceramic and polymer materials are fused and deposited. The properties of the composites can be tailored by changing the connectivity of the phases

PLA and hydroxyapatite are mixed and sintered by SLS RP to fabricate tissue scaffolds. Layer thickness is $50 \mu \mathrm{m}$
1. Good mechanical strength; easy control of material composition.

2. High temperature, complex controlling system, and shielding gas involved; materials must be in powder form.

1. Good porosity control, good mechanical strength.

2. High temperature, complex controlling system, materials must be in powder.

1. good control of composition and location of deposition

2. complex controlling system, lower mechanical strength

1. Good control of composition, good implementation of tissue scaffold.

2. Expensive equipment, higher temperature, difficult to remove the loose powder within pores 
On the other hand, there a lot of disadvantages and challenges have been studied too through the literature of AM technology; some of them are provided as follows $[74,75]$ :

I. The misunderstanding consideration for using rapid prototyping technique for fabrication of prototypes only as it can be used in producing finished products.

II. Different resolution and properties for $X Y Z$ directions because of nonlinear behavior of AM proposed parts.

III. The nature of rectangular slicing layer cannot conform to the curved surface, so bad surface quality and roughnesses of produced parts are observed. This phenomenon is called "stair-stepping".

IV. Adequate strength and accuracy for metallic parts are required through development of direct manufacturing techniques.

$\mathrm{V}$. Increase the applied domain of AM proposed materials.

VI. Higher AM system cost.

VII. Disadvantages of support structures as it provides lower quality for the produced products and those structures are hard to recycle. The optimal build-up orientation is required to eliminate this problem.

VIII. More research needs to be done in area of layer thickness optimization as it effects on the processing time and needs larger data files.

A number of predictions as a future look for AM technology can be achieved through ongoing research and development in this field. Some of those predictions are provided as follows [74, 76]:

I. More potential users and demands and availability of AM technology will lead to low or medium cost AM systems within upcoming years.

II. The progress of materials and design process through increasing the speed of processing.

III. Capability of processing multiple materials within the same AM system.

\section{Conclusions}

In this study, a literature review on AM technology has been presented focusing on research, development and investigation of composite materials fabrication through additive manufacturing technology. During this study, different types of composite materials and potential alloys have been discussed such as; metal matrix composites, ceramic matrix composites, polymer matrix composites, and some metallic and polymer alloys. Different performance characteristics have been presented in order to prove the importance of AM rather than conventional manufacturing techniques. The main performance characteristics in almost studies are; mechanical properties, physical properties (e.g. relative density), tribological properties, and nature of developed microstructure. Furthermore, nano-composites fabrication and additive nano-manufacturing have been presented through discussing the additive manufacturing methods and features. One of the most effective AM proposed composite materials is functionally graded materials which have been discussed in this study as it offers the ability to control the composition and optimize the properties of the built part. Finally, obtaining opportunities, challenges and future look of AM has been provided as an important step to spread this smart manufacturing technique in various industries such as; biomedical, architectural, and building fields.

\section{References}

1. J.-P. Kruth, Material incress manufacturing by rapid prototyping techniques, CIRP Annals - Manufacturing Technology 40 (1991) 603-614.

2. J.-P. Kruth, M.-C. Leu, T. Nakagawa, Progress in additive manufacturing and rapid prototyping, CIRP Annals - Manufacturing Technology 47 (1998) 525-540.

3. W.D. Callister, D.G. Rethwisch, Materials science and engineering: an introduction, vol. 7, Wiley, New York, 2007.

4. D. Bourell, M. Leu, D. Rosen, Roadmap for additive manufacturing-Identifying the future of freeform processing, vol. 32, The University of Texas at Austin, Laboratory for Freeform Fabrication. Advanced Manufacturing Center, 2009.

5. I. Gibson, D.W. Rosen, B. Stucker, Additive manufacturing technologies, Springer, New York, 2010.

6. T.J. Horn, O.L. Harrysson, Overview of current additive manufacturing technologies and selected applications, Science Progress 95 (2012) 255-282.

7. N. Guo, M.C. Leu, Additive manufacturing: technology, applications and research needs, Frontiers of Mechanical Engineering 8 (2013) 215-243.

8. S. Mellor, L. Hao, D. Zhang, Additive manufacturing: a framework for implementation, International Journal of Production Economics 149 (2014) 194-201.

9. S.H. Huang, et al., Additive manufacturing and its societal impact: a literature review, The International Journal of Advanced Manufacturing Technology 67 (2013) 1191-1203.

10. W.E. Frazier, Metal additive manufacturing: a review, Journal of Materials Engineering and Performance 23 (2014) 1917-1928.

11. V. Petrovic, et al., Additive layered manufacturing: sectors of industrial application shown through case studies, International Journal of Production Research 49 (2011) 1061-1079.

12. H.R. Thomas, N. Hopkinson, P. Erasenthiran, High speed sintering - continuing research into a new rapid manufacturing process, in Proceedings of 17 th SFF Symposium, Austin, TX, 2006.

13. S. Kumar, Development of functionally graded materials by ultrasonic consolidation, CIRP Journal of Manufacturing Science and Technology 3 (2010) 85-87.

14. C. Cheah, et al., Rapid prototyping and tooling techniques: a review of applications for rapid investment casting, The International Journal of Advanced Manufacturing Technology 25 (2005) 308-320.

15. L.E. Murr, et al., Characterization of titanium aluminide alloy components fabricated by additive manufacturing using electron beam melting, Acta Materialia 58 (2010) 1887-1894. 
16. A. Gasser, et al., Laser additive manufacturing, Laser Technik Journal 7 (2010) 58-63.

17. M.C. Leu, S. Pattnaik, G.E. Hilmas, Optimization of selective laser sintering process for fabrication of zirconium diboride parts, in Proceeding of International Solid Freeform Fabrication Symposium, Austin, TX, 2010.

18. S. Das, et al., Producing metal parts with selective laser sintering/hot isostatic pressing, JOM 50 (1998) 17-20.

19. A. Strondl, et al., Microstructure and mechanical properties of nickel based superalloy IN718 produced by rapid prototyping with electron beam melting (EBM), Materials Science and Technology 27 (2011) 876-883.

20. M. El Baradie, Manufacturing aspects of metal matrix composites, Journal of Materials Processing Technology 24 (1990) 261-272.

21. B. Vandenbroucke, J.-P. Kruth, Selective laser melting of biocompatible metals for rapid manufacturing of medical parts, Rapid Prototyping Journal 13 (2007) 196-203.

22. R. Hahnlen, M.J. Dapino, Active metal-matrix composites with embedded smart materials by ultrasonic additive manufacturing, in SPIE Smart Structures and Materials + Nondestructive Evaluation and Health Monitoring, International Society for Optics and Photonics, 2010.

23. D. Gu, et al., Laser additive manufacturing of metallic components: materials, processes and mechanisms, International Materials Reviews 57 (2012) 133-164.

24. C. Paul, et al., Investigating laser rapid manufacturing for Inconel-625 components, Optics \& Laser Technology 39 (2007) 800-805.

25. S. Bhattacharya, et al., Microstructural evolution of AISI 4340 steel during direct metal deposition process, Materials Science and Engineering: A 528 (2011) 2309-2318.

26. G. Dinda, L. Song, J. Mazumder, Fabrication of Ti-6Al-4V scaffolds by direct metal deposition, Metallurgical and Materials Transactions A 39 (2008) 2914-2922.

27. B. Baufeld, O. Van der Biest, R. Gault, Additive manufacturing of $\mathrm{Ti}-6 \mathrm{Al}-4 \mathrm{~V}$ components by shaped metal deposition: microstructure and mechanical properties, Materials \& Design 31 (2010) S106-S111.

28. N. Fang, Q. Wu, A comparative study of the cutting forces in high speed machining of Ti-6Al-4V and Inconel 718 with a round cutting edge tool, Journal of Materials Processing Technology 209 (2009) 4385-4389.

29. E. Brandl, et al., Additive manufactured AlSi10Mg samples using Selective Laser Melting (SLM): microstructure, high cycle fatigue, and fracture behavior, Materials \& Design 34 (2012) 159-169.

30. A. Emamian, S.F. Corbin, A. Khajepour, The effect of powder composition on the morphology of in situ TiC composite coating deposited by Laser-Assisted Powder Deposition (LAPD), Applied Surface Science 261 (2012) 201-208.

31. A. Emamian, M. Alimardani, A. Khajepour, Effect of cooling rate and laser process parameters on additive manufactured Fe-Ti-C metal matrix composites microstructure and carbide morphology, Journal of Manufacturing Processes 16 (2014) 511-517.

32. R. Chou, et al., Additive manufacturing of Al-12Si alloy via pulsed selective laser melting, JOM 67 (2015) 590-596.

33. A. Bellini, L. Shor, S.I. Guceri, New developments in fused deposition modeling of ceramics, Rapid Prototyping Journal 11 (2005) 214-220.
34. E. Sachs, et al., Three dimensional printing: rapid tooling and prototypes directly from a CAD model, Journal of Engineering for Industry 114 (1992) 481-488.

35. K. Fan, W. Cheung, I. Gibson, Fusion behavior of TrueForm ${ }^{\mathrm{TM}} /$ $\mathrm{SiO}_{2}$ composite powders during selective laser sintering, Rapid Prototyping Journal 14 (2008) 87-94.

36. F.-H. Liu, Y.-K. Shen, Y.-S. Liao, Selective laser gelation of ceramic-matrix composites, Composites Part B: Engineering 42 (2011) 57-61.

37. A.E. Tontowi, T. Childs, Density prediction of crystalline polymer sintered parts at various powder bed temperatures, Rapid Prototyping Journal 7 (2001) 180-184.

38. J. Wilkes, et al., Additive manufacturing of $\mathrm{ZrO}_{2}-\mathrm{Al}_{2} \mathrm{O}_{3}$ ceramic components by selective laser melting, Rapid Prototyping Journal 19 (2013) 51-57.

39. B. Cappi, et al., Direct inkjet printing of Si 3 N 4: characterization of ink, green bodies and microstructure, Journal of the European Ceramic Society 28 (2008) 2625-2628.

40. A.M. Wätjen, et al., Novel prospects and possibilities in additive manufacturing of ceramics by means of direct inkjet printing, Advances in Mechanical Engineering 6 (2014) 141346.

41. M. Schwentenwein, J. Homa, Additive manufacturing of dense alumina ceramics, International Journal of Applied Ceramic Technology 12 (2015) 1-7.

42. H.L. Tekinalp, et al., Highly oriented carbon fibe-polymer composites via additive manufacturing, Composites Science and Technology 105 (2014) 144-150.

43. L.J. Love, et al., The importance of carbon fiber to polymer additive manufacturing, Journal of Materials Research 29 (2014) 1893-1898.

44. J.B. Jones, D.I. Wimpenny, G.J. Gibbons, Additive manufacturing under pressure, Rapid Prototyping Journal 21 (2015) 89-97.

45. S. Kenzari, et al., Quasicrystal-polymer composites for additive manufacturing technology, Acta Physica Polonica A 126 (2014) 449-452.

46. I. Gorynin, et al., Additive technologies based on composite powder nanomaterials, Metal Science and Heat Treatment 56 (2015) 519-524.

47. I. Shishkovsky, Laser synthesis of functionally gradient mesostructures and bulk products, Fizmatlit, Moscow, 2009, p. 424.

48. B. Zheng, et al., Microstructure and properties of laserdeposited Ti6A14V metal matrix composites using Ni-coated powder, Metallurgical and Materials Transactions A 39 (2008) 1196-1205.

49. R. Gadow, F. Kern, A. Killinger, Manufacturing technologies for nanocomposite ceramic structural materials and coatings, Materials Science and Engineering: B 148 (2008) 58-64.

50. D. Engstrom, et al., Additive nanomanufacturing - a review, Journal of Materials Research 29 (2014) 1792-1816.

51. D.J. Pena, M.P. Raphael, J.M. Byers, "Dip-Pen" nanolithography in registry with photolithography for biosensor development, Langmuir 19 (2003) 9028-9032.

52. P. Galliker, et al., Direct printing of nanostructures by electrostatic autofocussing of ink nanodroplets, Nature Communications 3 (2012) 890.

53. J. Zhang, et al., Design, manufacturing, and testing of singlecarbon-nanotube-based infrared sensors, Nanotechnology, IEEE Transactions on 8 (2009) 245-251. 
54. O. Ivanova, C. Williams, T. Campbell, Additive manufacturing (AM) and nanotechnology: promises and challenges, Rapid Prototyping Journal 19 (2013) 353-364.

55. D. Gu, H. Wang, G. Zhang, Selective laser melting additive manufacturing of Ti-based nanocomposites: The role of nanopowder, Metallurgical and Materials Transactions A 45 (2014) 464-476.

56. L. Li, W. Syed, A. Pinkerton, Rapid additive manufacturing of functionally graded structures using simultaneous wire and powder laser deposition, Virtual and Physical Prototyping 1 (2006) 217-225.

57. V. Beal, et al., Evaluating the use of functionally graded materials inserts produced by selective laser melting on the injection moulding of plastics parts, Proceedings of the Institution of Mechanical Engineers, Part B: Journal of Engineering Manufacture 221 (2007) 945-954.

58. M. Domack, J. Baughman, Development of nickel-titanium graded composition components, Rapid Prototyping Journal 11 (2005) 41-51.

59. E. Müller, et al., Functionally graded materials for sensor and energy applications, Materials Science and Engineering: A 362 (2003) 17-39.

60. H. Chung, S. Das, Functionally graded Nylon-11/silica nanocomposites produced by selective laser sintering, Materials Science and Engineering: A 487 (2008) 251-257.

61. C.-Q. Hong, et al., A novel functionally graded material in the $\mathrm{ZrB} \mathrm{2-SiC}$ and $\mathrm{ZrO} 2$ system by spark plasma sintering, Materials Science and Engineering: A 498 (2008) 437-441.

62. J. Parthasarathy, B. Starly, S. Raman, A design for the additive manufacture of functionally graded porous structures with tailored mechanical properties for biomedical applications, Journal of Manufacturing Processes 13 (2011) 160-170.

63. G. Jin, W. Li, Adaptive rapid prototyping/manufacturing for functionally graded material-based biomedical models, The International Journal of Advanced Manufacturing Technology 65 (2013) 97-113.

64. J. Obielodan, B. Stucker, A fabrication methodology for dualmaterial engineering structures using ultrasonic additive manufacturing, The International Journal of Advanced Manufacturing Technology 70 (2014) 277-284.

65. K. Arcaute, B. Mann, R. Wicker, Stereolithography of spatially controlled multi-material bioactive poly (ethylene glycol) scaffolds, Acta Biomaterialia 6 (2010) 1047-1054.

66. P. Dewhurst, A general optimality criterion for strength and stiffness of dual-material-property structures, International journal of mechanical sciences 47 (2005) 293-302.

67. W. Han, et al., Tool path-based deposition planning in fused deposition processes, Journal of Manufacturing Science and Engineering 124 (2002) 462-472.

68. L. Hao, et al., Selective laser sintering of hydroxyapatite reinforced polyethylene composites for bioactive implants and tissue scaffold development, Proceedings of the Institution of Mechanical Engineers, Part H: Journal of Engineering in Medicine 220 (2006) 521-531.

69. A. Yakovlev, et al., Laser-assisted direct manufacturing of functionally graded 3D objects, Surface and Coatings Technology 190 (2005) 15-24.

70. T. Jackson, et al., Modeling and designing functionally graded material components for fabrication with local composition control, Materials \& Design 20 (1999) 63-75.

71. S. Kumar, J.-P. Kruth, Composites by rapid prototyping technology, Materials \& Design 31 (2010) 850-856.

72. D. Hotza, C.M. Gomes, J. Günster, Advances in additive manufacturing processes and materials, Advances in Mechanical Engineering 6 (2014) 645075.

73. S.K. Jing, et al., A review of product design for additive manufacturing, in Applied Mechanics and Materials, Trans Tech Publ., 2014.

74. I. Campbell, D. Bourell, I. Gibson, Additive manufacturing: rapid prototyping comes of age, Rapid Prototyping Journal 18 (2012) 255-258.

75. T. Grimm, User's guide to rapid prototyping, Society of Manufacturing Engineers, 2004.

76. K.V. Wong, A. Hernandez, A review of additive manufacturing, ISRN Mechanical Engineering 2012 August 16 (2012).

Cite this article as: Hegab HA: Design for additive manufacturing of composite materials and potential alloys: a review. Manufacturing Rev. 2016, 3, 11. 